\section{Federation University ResearchOnline}

\section{https://researchonline.federation.edu.au}

Copyright Notice

(C) 2018. This manuscript version is made available under the CC-BY-NC-ND 4.0 license http://creativecommons.org/licenses/by-nc-nd/4.0/

Li, Lok, J. B., Gasser, R. B., Korhonen, P. K., Sandeman, M. R., Shi, D., Zhou, R., Li, X., Zhou, Y., Zhao, J., \& Hu, M. (2014). Hc-daf-2 encodes an insulin-like receptor kinase in the barber's pole worm, Haemonchus contortus, and restores partial dauer regulation. International Journal for Parasitology, 44(7), 485-496.

Which has been published in final form at:

https://doi.org/10.1016/j.ijpara.2014.03.005 
Published in final edited form as:

Int J Parasitol. 2014 June ; 44(7): 485-496. doi:10.1016/j.ijpara.2014.03.005.

\title{
Hc-daf-2 encodes an insulin-like receptor kinase in the barber's pole worm, Haemonchus contortus, and restores partial dauer regulation
}

\author{
Facai Li ${ }^{\mathrm{a}}$, James B. Lok ${ }^{\mathrm{b}}$, Robin B. Gasser ${ }^{\mathrm{c}, \mathrm{d}}$, Pasi K. Korhonen ${ }^{\mathrm{c}}$, Mark R. Sandeman ${ }^{\mathrm{e}}$, \\ Deshi Shia ${ }^{\mathrm{a}}$, Rui Zhou ${ }^{\mathrm{a}}$, Xiangrui Li ${ }^{\dagger}$, Yanqin Zhou ${ }^{\mathrm{a}}$, Junlong Zhao ${ }^{\mathrm{a}}$, and Min Hua, \\ aState Key Laboratory of Agricultural Microbiology, Key Laboratory of Development of Veterinary \\ Diagnostic Products, Ministry of Agriculture, College of Veterinary Medicine, Huazhong \\ Agricultural University, 1 Shizishan Street, Wuhan 430070, Hubei, China \\ ${ }^{b}$ Department of Pathobiology, School of Veterinary Medicine, University of Pennsylvania, 3800 \\ Spruce Street, Philadelphia, PA 19104, USA \\ 'Faculty of Veterinary Science, The University of Melbourne, Corner of Flemington Road and \\ Park Drive, Parkville, Victoria 3010, Australia \\ IInstitute of Parasitology and Tropical Veterinary Medicine, Freie Universität Berlin, 16-18 \\ Kaiserswerther Street, Berlin 14195, Germany \\ eSchool of Applied Sciences and Engineering, Monash University, Northways Road, Churchill, \\ Victoria 3842, Australia \\ ${ }^{f}$ College of Veterinary Medicine, Nanjing Agricultural University, 1 Weigang, Nanjing 210095, \\ Jiangsu, China
}

\begin{abstract}
Infective L3s (iL3s) of parasitic nematodes share common behavioural, morphological and developmental characteristics with the developmentally arrested (dauer) larvae of the free-living nematode Caenorhabditis elegans. It is proposed that similar molecular mechanisms regulate entry into or exit from the dauer stage in C. elegans, and the transition from free-living to parasitic forms of parasitic nematodes. In C elegans, one of the key factors regulating the dauer transition is the insulin-like receptor (designated Ce-DAF-2) encoded by the gene Ce-daf-2. However, nothing is known about DAF-2 homologues in most parasitic nematodes. Here, using a PCR-based approach, we identified and characterised a gene (Hc-daf-2) and its inferred product (Hc-DAF-2) in Haemonchus contortus (a socioeconomically important parasitic nematode of ruminants). The sequence of $\mathrm{Hc}$-DAF-2 displays significant sequence homology to insulin receptors (IR) in both vertebrates and invertebrates, and contains conserved structural domains. A sequence encoding an important proteolytic motif (RKRR) identified in the predicted peptide sequence of $\mathrm{Hc}$-DAF-2 is consistent with that of the human IR, suggesting that it is involved in the formation of the IR
\end{abstract}

*Corresponding author. Tel.: +86 27 87280032; fax: +86 27 87280408, mhu@ mail.hzau.edu.cn (M. Hu). Appendix A. Supplementary data: Supplementary data associated with this article can be found, in the online version, at http:// dx.doi.org/10.1016/j.ijpara.2014.03.005. 
complex. The Hc-daf-2 gene was transcribed in all life stages of $H$. contortus, with a significant up-regulation in the iL3 compared with other stages. To compare patterns of expression between $\mathrm{Hc}$-daf-2 and Ce-daf-2, reporter constructs fusing the Ce-daf-2 or Hc-daf-2 promoter to sequence encoding GFP were microinjected into the $\mathrm{N} 2$ strain of $C$. elegans, and transgenic lines were established and examined. Both genes showed similar patterns of expression in amphidial (head) neurons, which relate to sensation and signal transduction. Further study by heterologous genetic complementation in a daf-2-deficient strain of $C$. elegans (CB1370) showed partial rescue of function by $\mathrm{Hc}$-daf-2. Taken together, these findings provide a first insight into the roles of $\mathrm{Hc}$ $d a f-2 / H c-D A F-2$ in the biology and development of $H$. contortus, particularly in the transition to parasitism.

\section{Keywords}

Parasitic nematode; Haemonchus contortus; daf-2; Development; Transgenesis

\section{Introduction}

Parasitic roundworms (=nematodes) are important pathogens in both human beings and innumerable domestic and wild animals. It is estimated that more than $10 \%$ of the world's animal populations are threatened by these parasitic diseases and, each year, major economical losses result from morbidity, reduced production and mortality in livestock globally (Crompton, 1999; Hotez et al., 2009). As there is no effective vaccine available, treatment of these diseases relies heavily on anthelmintic drugs (Wolstenholme et al., 2004). However, the widespread use of these anthelmintic drugs has resulted in serious drug resistance problems worldwide in some parasitic nematodes of animals (Kaplan, 2004; Schnyder et al., 2005; Gilleard and Beech, 2007; Geary et al., 2010; Papadopoulos et al., 2012). Therefore, it is imperative to develop new intervention strategies. One of the possibilities is the rational design of anti-parasite drugs and/or vaccines, built on the deep understanding of the biological and developmental processes in these parasites. For instance, for parasitic nematodes, clear insights into the developmental transition from free-living to parasitic stages (Blaxter et al., 1996; Cantacessi et al., 2010) might identify key switches as new drug targets (Lizotte-Waniewski et al., 2000; Godel et al., 2012).

The characterisation of the nuclear genomes and transcriptomes of some key parasitic nematodes including Ascaris suum (see Jex et al., 2011), Brugia malayi (see Ghedin et al., 2007), Dirofilaria immitis (see Godel et al., 2012), Haemonchus contortus (see Laing et al., 2013; Schwarz et al., 2013), Loa loa (see Desjardins et al., 2013) and Necator americanus (see Tang et al., 2014) provides a solid foundation for investigating developmental processes using complementary molecular (i.e. genetic, genomic, proteomic and metabolomic) tools. However, a lack of effective genetic and genomic tools for some parasitic nematodes and an inability to maintain their entire life cycle in the laboratory (Boyle and Yoshino, 2003; Aboobaker and Blaxter, 2004; Gilleard, 2004; Britton and Murray, 2006; Kalinna and Brindley, 2007; Knox et al., 2007; Maule et al., 2011) hampers detailed functional studies. In contrast, Caenorhabditis elegans can be readily maintained in the laboratory and used to explore fundamental processes and mechanisms such as dauer formation $(\mathrm{Hu}, 2007)$. This 
free-living nematode belongs to clade V (Blaxter et al., 1998) and is relatively closely related to H. contortus. Published information (Blaxter, 1998; Bürglin et al., 1998; Hashmi et al., 2001; Gilleard, 2004; Britton and Murray, 2006) also indicates similarity in dauer induction and recovery between $C$. elegans and strongylids. The dauer state occurs in $C$. elegans when the nematode encounters unfavourable environmental conditions including high temperature, starvation and/or crowding (Golden and Riddle, 1984; Riddle and Albert, 1997). The dauer form can survive for several months and resume development to reproductive adults when the environmental conditions improve (Golden and Riddle, 1984). Consistent with C. elegans, strongylid nematodes have a similar infective L3 (iL3), which is resistant to unfavourable conditions and does not feed because it is enveloped by a sheath (Hotez et al., 1993). The "dauer hypothesis" or "daf-c paradigm" holds that the resumption of iL3 development in parasitic nematodes is developmentally and functionally analogous to the recovery from the dauer state in C. elegans and is governed by similar molecular mechanisms (Hotez et al., 1993; Blaxter, 1998; Bürglin et al., 1998; Hu, 2007). Dauer development is regulated by several signalling pathways including an insulin/insulin-like growth factor 1 (IGF1)-like signalling pathway, which contains a number of components such as the insulin-like receptor kinase DAF-2 (Kimura et al., 1997; Apfeld and Kenyon, 1998; Gems et al., 1998), the Phosphoinositide-3 (PI3) kinase AGE-1 (Vanhaesebroeck et al., 1997; Engelman et al., 2006; Ayyadevara et al., 2009) and the FOXO-class transcription factor DAF-16 (Lin et al., 1997; Ogg et al., 1997; Ogg and Ruvkun, 1998). Mutations in the daf-2 and age-1 genes result in dauer constitutive (daf-c) phenotypes, whereas mutations in daf-16 give dauer-defective (daf-d) phenotypes. Signalling through DAF-2 activates AKT-1/2 by phosphorylation which, in turn, negatively regulates DAF-16, which functions as a central mediator of multiple biological processes including longevity, development and stress resistance (Mukhopadhyay et al., 2006; Yen et al., 2011).

Using homology and PCR-based tools, components of the insulin/IGF1-like signalling (IIS) pathway have been cloned and characterised from parasitic nematodes, including Ancylostoma caninum (see Gao et al., 2009; Gelmedin et al., 2011), H. contortus (see Hu et al., 2010) and Strongyloides stercoralis (see Massey et al., 2003, 2006). For instance, we have shown that $H$. contortus expresses two isoforms of a functionally conserved $C$. elegans DAF-16 orthologue (Hu et al., 2010). This finding suggests that the IIS pathway is relatively conserved and might regulate developmental processes in $H$. contortus. However, nothing is known about other components of the IIS pathways in this parasitic nematode. In the present study, we isolated and characterised the $d a f-2$ orthologue of $H$. contortus (Hc-daf-2). Using in vitro and in vivo systems, we also explored transcription of $\mathrm{Hc}$-daf-2 in different developmental stages of $H$. contortus and function in $C$. elegans by heterologous gene rescue.

\section{Materials and methods}

\subsection{Ethics statement}

All of the experimental animals used in this project were treated in strict accordance with the recommendations in the Guide for the Regulation for the Administration of Affairs Concerning Experimental Animals of the People's Republic of China. The protocol was 
approved by the Committee on the Ethics of Animal Experiments of Hubei Province (Permit Number: SYXK-0029). The care and maintenance of animals were in accordance with government guidelines.

\subsection{Caenorhabditis elegans and $H$. contortus strains, and their maintenance}

Caenorhabditis elegans strains were obtained from the Caenorhabditis Genetic Center (CGC) (University of Minnesota, USA), including the wild-type N2 and a daf-2 mutant strain (e1370) which is a temperature-sensitive dauer constitutive allele with $100 \%$ dauers at $25^{\circ} \mathrm{C}$. These worms were maintained by standard protocols (Stiernagle, 2006) on nematode growth medium (NGM) plates with Escherichia coli OP50 lawns at $15^{\circ} \mathrm{C}$. The Haecon 5 strain of $H$ contortus was maintained by serial passage in 3-6 month old helminth-free goats which were infected intraruminally with 10,000 iL3s. Eggs were isolated from the infected goat faeces using an established sucrose flotation method (Cox and Todd, 1962). The L1s, L2s and iL3s were harvested from Baermann funnel apparatus after 1, 3 and 7 days of incubation of faeces at $28{ }^{\circ} \mathrm{C}$, respectively, and purified by repeated sedimentation and migration through a nylon sieve (mesh size: $25 \mu \mathrm{m}$ ). The L4s and adults of $H$. contortus were collected at necropsy from the abomasa of infected goats euthanised with an overdose of pentobarbitone sodium (Lethobarb, Virbac Pty. Ltd, Australia) at 8 or 30 days of infection, respectively. Parasites in the two developmental stages were washed extensively in physiological saline to remove debris, and males and females separated prior to snap freezing in liquid nitrogen and subsequent storage at $-80^{\circ} \mathrm{C}$.

\subsection{DNA and RNA preparation}

Caenorhabditis elegans genomic DNA was extracted from a mixed-stage culture of N2strain worms by using an EasyPure Genomic DNA Kit (TransGen Biotech, Beijing, China). Haemonchus contortus genomic DNA was isolated from a large number of iL3s using the same procedure. Total RNA was isolated from different stages or sexes of $H$. contortus (egg, L1, L2, iL3, L4 female and male, adult female and male) using TRIzol (Life Technologies, USA) following the manufacturer's instructions. RNA integrity and yields were verified by electrophoresis and spectrophotometry (Nano Drop Technologies, USA), respectively. Extracted total RNA was treated with RQ1-RNase-Free DNase (Promega, USA). Isolated DNA and RNA were stored at $-80{ }^{\circ} \mathrm{C}$ until use.

\subsection{Isolation and sequencing of the full-length Hc-daf-2 cDNA}

Using two highly degenerate primers, DAF-2/F and DAF-2/R (primer sequences are listed in Supplementary Table S1), designed from regions of conserved motifs within tyrosine kinase (TK) domains of five insulin-receptor (IR) sequences (species and Gen-Bank accession nos: Homo sapiens BC143721, Canis familiaris XM_853228, Paralichthys adspersus FJ438475, Xenopus laevis BC170428 and C. elegans Y55D5A.5), a 150 bp fragment was amplified from cDNA synthesised from total RNA extracted from adult $H$. contortus. This PCR product was cloned into the pGEM-T-Easy vector (Promega) and sequenced. Based on the isolated sequence, four gene-specific primers, Hc-daf-2/1F, Hc-daf-2/2R, Hc-daf-2/3F and Hc-daf-2/4R, were designed (Supplementary Table S1). Using pairs of gene-specific primers and adaptor primers, two partially overlapping cDNA fragments were produced separately 
from total RNA from adult $H$. contortus by $5^{\prime}$-and $3^{\prime}$-rapid amplification of cDNA ends (RACE) (SMARTer ${ }^{\mathrm{TM}}$ RACE cDNA Amplification Kit, Clontech, USA). In order to obtain the complete $5^{\prime}$-end of the $\mathrm{Hc}$-daf-2 cDNA, gene-specific primers Hc-daf-2/6R and Hcdaf-2/7R (Supplementary Table S1) were designed and used in two rounds of PCR amplification by $5^{\prime}$-RACE. These cDNAs were cloned into the pGEM-T-Easy vector and sequenced. Finally, using the primers Hc-daf-2/F200, Hc-daf-2/R200, Ce-daf-2/F200 and Ce-daf-2/R200 (Supplementary Table S1), the full-length $\mathrm{Hc}$-daf-2 and Ce-daf-2 cDNA fragments were amplified by 5'-RACE, cloned into a pGEM-T-Easy vector (Promega) and sequenced.

\subsection{Isolation of the full-length genomic DNA and the putative promoter region of Hc-daf-2}

The full-length genomic DNA sequence of Hc-daf-2 was amplified by long-range PCR (Advantage 2 PCR Polymerase Kit, BD Bio-science) employing eight primers designed based on the cDNA sequence of $H c$-daf-2 (GenBank accession number KJ147513) including Hc-daf-2/36F, D2R1, A7F, Hc-daf-2/48R, Hc-daf-2/29F, D2R2, D2F2, B4R, A4F, B3R, A3F, D2R4, A1F, Hc-daf-2/52R, Hc-daf-2/3F, Hc-daf-2/22R (Supplementary Table S1). Eight overlapping fragments were produced and cloned into the pMD19-T vector (Takara, Japan) and sequenced. The sequences obtained were assembled manually. This full genomic DNA sequence has $93 \%$ identity to the $H c-d a f-2$ gene sequence in a published genome sequence (GenBank accession number HF964392.1; cf. Laing et al., 2013).

To isolate the promoter region of $H c-d a f-2$, four $H$. contortus genome walker libraries were constructed using the GenomeWalker ${ }^{\mathrm{TM}}$ Universal Kit (Clontech) following the manufacturer's instructions. The $5^{\prime}$ flanking region of $\mathrm{Hc}$-daf-2 was amplified by two rounds of long-range PCR (Advantage 2 PCR Polymerase Kit, Clontech) according to the manufacturer's protocol. The primary PCR used the outer adaptor primer (AP1) provided in the kit and gene-specific primer (Hc-daf-2/10R, Supplementary Table S1) designed based on genomic DNA sequence of Hc-daf-2 (GenBank accession number KJ147513) and the four GenomeWalker ${ }^{\mathrm{TM}}$ Libraries as templates. The cycling conditions were: $94{ }^{\circ} \mathrm{C}, 25 \mathrm{~s} ; 72{ }^{\circ} \mathrm{C}, 3$ min for seven cycles, then $94{ }^{\circ} \mathrm{C}, 25 \mathrm{~s} ; 67^{\circ} \mathrm{C}, 3 \mathrm{~min}$ for 32 cycles, and a final extension at $67{ }^{\circ} \mathrm{C}$ for an additional $7 \mathrm{~min}$. The primary PCR product was diluted and used as a template for a nested PCR with the nested adaptor primer (AP2) and a nested gene-specific primer (Hc-daf-2/8R, Supplementary Table S1). The cycling conditions were: $94{ }^{\circ} \mathrm{C}, 25 \mathrm{~s} ; 72{ }^{\circ} \mathrm{C}, 3$ min for five cycles, then $94^{\circ} \mathrm{C}, 25 \mathrm{~s} ; 67^{\circ} \mathrm{C}, 3 \mathrm{~min}$ for 20 cycles, and a final extension at 67 ${ }^{\circ} \mathrm{C}$ for an additional $7 \mathrm{~min}$. After PCR amplification, the PCR product was electrophoresed and visualised on a $1 \%$ agarose gel from which a single, major band with little background was excised, cloned into a pGEM-T-Easy vector and sequenced. To isolate the entire promoter sequence, two primers (Hc-daf-2/54F and Hc-daf-2/PAGER, Supplementary Table S1) located in the $5^{\prime}$ - and $3^{\prime}$ - end, respectively, were designed and applied to amplify the merged sequence. The resulting $3184 \mathrm{bp} \mathrm{PCR}$ product, representing the promoter of $\mathrm{Hc}$ daf-2 in its entirety, was cloned into a pGEM-T-Easy vector and sequenced.

\subsection{Bioinformatic and phylogenetic analyses}

Nucleotide sequences were assembled using CAP3 (http://bio.ifom-firc.it/ASSEMBLY/ assemble.html) and compared with those in non-redundant databases using the BLAST v.2.0 
suite of programs from the National Center for Biotechnology Information (NCBI, USA) (http://www.ncbi.nlm.nih.gov/BLAST), the Sanger Centre (www.sanger.ac.uk) and the Parasite Genome database (www.ebi.ac.uk) to confirm the identity of genes isolated. The conceptual translation of individual cDNAs into amino acid (aa) sequences was performed using the selection "translate", available at http://bioinformatics.org/. Protein motifs were identified by scanning the databases Pfam (www.sanger.ac.uk/Software/Pfam) and PROSITE (www.expasy.ch/tools/scnpsit1.html). Signal sequences were predicted using SignalP v2.0 (Nielsen et al., 1997), available at the Center for Biological Sequence Analysis (www.cbs.dtu.dk/services/SignalP). The aa sequence alignments were carried out using Clustal W (Thompson et al., 1994) and adjusted by manual inspection. Promoter elements in the 5'-untranslated region (UTR) were predicted using the transcription element search system (PLACE; available at http://www.dna.affrc.go.jp/PLACE/signalscan.html).

The aa sequences inferred for Hc-DAF-2 (GenBank accession number KJ147513) and 23 selected sequences from homologues of other invertebrates and vertebrates were subjected to phylogenetic analyses. The phylogenetic analysis was conducted using the neighbourjoining (NJ), maximum parsimony (MP) and maximum likelihood (ML) methods, respectively, based on the Jones-Taylor-Thornton (JTT) model (Tamura et al., 2011). Confidence limits were assessed using a bootstrap procedure with 1000 pseudo-replicates for NJ, MP and ML trees, and other settings were obtained using the default values in MEGA v.5.0. A 50\% cut-off value was implemented for the consensus tree.

\subsection{Transcript abundance based on RNA-seq analysis}

Transcriptomic data for different developmental stages (eggs, L1s, L2s, iL3s, L4s and adults) and sexes (males and females) of $H$. contortus (Haecon-5 strain, Australia) produced previously by RNA-seq were publicly available (Schwarz et al., 2013). The analysis of transcription of $\mathrm{Hc}$-daf-2 was carried out as described previously (Mortazavi et al., 2010; Schwarz et al., 2013).

\subsection{Transformation constructs}

Using overlap extension PCR (Nelson and Fitch, 2011; Stoltzfus et al., 2012a), two constructs designated pL-CG2 and pL-HG2 (Fig. 1) fusing either the Ce-daf-2 or Hc-daf-2 promoter to the $g f p$ coding sequence and the Ce-unc-54 terminator $(t)$, were assembled in two steps. Firstly, the upstream regions of each gene using the primers Ce-daf-pro-F, Cedafage-3R and Hc-daf-2/54F, Hc-daf-2/PAGER (2759 bp for Ce-daf-2 and $3184 \mathrm{bp}$ for $\mathrm{Hc}$ $d a f-2)$ were amplified from $C$. elegans and $H$. contortus genomic DNA, respectively. The $1777 \mathrm{bp}$ fragment containing the $g f p$ coding region with introns and Ce-unc-54t were then amplified from C. elegans vector pPD95.75. Secondly, the hybrid genes were fused by overlap extension PCR with primers Ce-daf-gfp-3F, Ce-daf-gfp-4R, Hc-daf-gfp-1F and Hcdaf-gfp-2R (Supplementary Table S1), respectively. Each amplified PCR product was cloned into the pGEM-T-Easy vector and sequenced.

For the dauer switching assay, the rescuing constructs Ce-daf-2 p: :Ce-daf-2(5541bp): :Ceunc-54t (designated pL-CD2, Fig. 1) and Hc-daf-2 p: :Hc-daf-2(4215bp): :Ce-unc-54t (designated pL-HD2, Fig. 1) were made using pPV238 (Massey et al., 2013) as starting 
material. Briefly, the $g f p$ reporter was removed from pPV238 by restriction digestion with enzymes AgeI (A) and BstZ17I (B), at sites located at the 5'-and 3'-termini, respectively. Then, the cDNA sequences of Ce-daf-2 and Hc-daf-2 tagged with these two restriction sites were amplified from plasmids (pGEM-Ce-daf-2 and pGEM-Hc-daf-2), and cloned into modified pPV238 to create rescuing vectors pL-CD2 and pL-HD2, respectively (Fig. 1).

\subsection{DNA transformation of $\mathrm{C}$. elegans and selection of the transgenic lines}

Standard gonadal microinjection of C. elegans was performed as described (Mello et al., 1991; Massey et al., 2006). In brief, injection mixes for C. elegans, including the test constructs (pL-CG2, pL-HG2, pL-CD2 and pL-HD2) and pRF4 containing the rol-6 marker gene were co-injected at a final concentration of $20 \mathrm{ng} / \mu \mathrm{l}$ and $80 \mathrm{ng} / \mu \mathrm{l}$, respectively. Microinjected worms were reared on NGM plates with lawns of E. coli OP50 and cultured at $15{ }^{\circ} \mathrm{C}$. Transformants were identified among their $\mathrm{F} 1$ progeny based on a "right-roller" phenotype and gene-specific reverse transcriptase (RT)-PCR detection. For the gene expression pattern assay, the screened transformants were anesthetised using $10 \mathrm{mM}$ levamisole, immobilised on a $2 \%$ agar pad and cell-specific expression was assessed by GFP expression under a stereoscopic fluorescence microscope and a compound fluorescence microscope equipped with Differential interference contrast (DIC) optics and a camera (Olympus BX51, Japan).

To verify transcription of transgene-specific mRNA, RT-PCR was carried out using daf-2specific primers in daf-2 (e1370) transgenic lines (Massey et al., 2006). Briefly, rollerworms were picked into TRIzol (Life Technologies) and placed at $-80{ }^{\circ} \mathrm{C}$. Then, RNA was treated with DNase I (Promega) and used as a template for RT-PCR. Gene-specific primers (Hc-daf-2/3F and Hc-daf-2/2R) were used to detect the presence of $\mathrm{Hc}$-daf-2 gene and Cerps-21F, Ce-rps-21R primers were used to detect the presence of Ce-rps-21 gene as a control, using one-step RT-PCR (Takara). The conditions were as follows: $50{ }^{\circ} \mathrm{C}, 30 \mathrm{~min}$; $94{ }^{\circ} \mathrm{C}, 2 \mathrm{~min}$; then $94{ }^{\circ} \mathrm{C}, 30 \mathrm{~s} ; 55^{\circ} \mathrm{C}, 30 \mathrm{~s} ; 68^{\circ} \mathrm{C}, 1 \mathrm{~min}$ for 35 cycles with a final extension $\left(68{ }^{\circ} \mathrm{C}, 5 \mathrm{~min}\right)$.

\subsection{Dauer-switching assay in C. elegans mutants}

To assess the effects of Hc-daf-2 expression on dauer switching in C. elegans, we used heterologous complementation phenotyping as described previously (Nolan et al., 2002; Massey et al., 2006; Crook et al., 2010; Hu et al., 2010). This assay evaluated development of semi-synchronised cohorts of worms at $25^{\circ} \mathrm{C}$. Mutant strains transformed with pRF4 were used as controls. In brief, semi-synchronous cohorts of eggs were prepared by plating 15-20 egg-laying hermaphrodites, transformed with either pL-CD2 or pL-HD2, on NGM plates with OP50 lawns. After 3-8 h, the adults were removed and the plates were incubated at $25^{\circ} \mathrm{C}$ for $65-70 \mathrm{~h}$. At the end of incubation, transgenic worms were identified based on right-roller phenotype and scored as non-dauer (L4s or adults) or dauer larvae. These assessments were made based on radial constriction of the body and on filariform pharyngeal morphology and lack of pharyngeal pumping (Riddle and Albert, 1997). Mean proportions of dauer larvae, partial dauers (which did not develop into adult worms, but exhibited pharyngeal pumping and other non-dauer morphological characteristics), and non- 
dauer individuals were calculated from at least three replicate assays of four independently derived lines. Proportions were compared by $\chi^{2}$ analysis.

\section{Results}

\subsection{Characterisation of the Hc-daf-2 cDNA}

The full-length $H c$-daf-2 cDNA, isolated by RACE from $H$. contortus, was 5463 bp in length, consisting of a $5^{\prime}$-UTR of $697 \mathrm{bp}$, a 3'-UTR of $551 \mathrm{bp}$ and a $4215 \mathrm{bp}$ region encoding a predicted protein of 1404 aa. Structural analysis using the programs BLAST, Motif Scan, Pfam and Clustal Omega predicted that the aa sequence of $\mathrm{Hc}$-DAF-2 has a high similarity (32 - 48\%) to homologues of various metazoans including C. elegans, A. suum, L. loa, Parastrongyloides trichosuri, S. stercoralis (nematodes), Danio rerio (zebra fish), Mus musculus (mouse) and Bos taurus (cattle). The alignment of homologues also showed that $H c$-DAF-2 possesses conserved domains, mainly in the extracellular and intracellular regions (Fig. 2A). In the extracellular region, two loop domains, L1 (from 55 to 175 aa) and L2 (from 363 to 467 aa), separated by a cysteine-rich region CR (from 176 to $362 \mathrm{aa}$ ), are typical features for IR family members, in which this structural arrangement constitutes the ligand-binding domain (Konrad et al., 2003) (Fig. 2A). The intracellular region of $\mathrm{Hc}$-DAF-2 consists of a transmembrane domain (TM) (from 989 to 1012 aa) and a conserved TK domain (from 1043 to 1329 aa), which are crucial for TK activity (Hanks and Hunter, 1995). In addition, three fibronectin 3 type domains (i.e. FN-1 from 502 to 619 aa, FN-2 from 633 to 676 aa, and FN-3 from 822 to 967 aa), which also belong to the extracellular region, were identified between the ligand binding and TM domains (Fig. 2A).

Further analysis identified several conserved sequence motifs in the intracellular domain of $\mathrm{Hc}$-DAF-2 that are considered crucial for insulin-like receptor function and interaction with downstream signalling molecules (Konrad et al., 2003). These highly conserved functional motifs in the intracellular region include an ATP binding site (GXGXXG) (Fig. 2B), a catalytic loop (the canonical HRDLAARN motif) and a $\mathrm{Mg}^{2+}$ binding site (DFG) (Fig. 2B). Significantly, the putative autophosphorylation motif (YXXXYY), which contains three tyrosine residues and is considered critical for kinase activity (White et al., 1988), was also identified in the intracellular domain of Hc-daf-2. In the juxtamembrane region, there is a highly conserved NPXY motif, which is essential for interaction with IR substrate factors (Gustafson et al., 1995) (Fig. 2B).

In the extracellular regions, sequence analysis identified an insert domain between FN-2 and FN-3, which contains an RKRR motif predicted to be a protease cleavage site required for the formation of the $\alpha_{2} \beta_{2}$ structure (Bravo et al., 1994; Ullrich et al., 1985). In the 779 aa a subunit (Fig. 1B) region of $\mathrm{Hc}$-DAF-2, there are eight consensus sequences for asparaginelinked glycosylation (Asn $\times$ Ser/Thr) (Ullrich et al., 1985) and an unusually large number $(n$ $=36$ ) of cysteine residues, 22 of which are located in CR domain. The 625 aa $\beta$ subunit (Fig. 2B) contains 10 cysteine residues and four potential asparagine-linked glycosylation sites (Fig. 2B). Interestingly, two residues (K and P; Fig. 2B, Supplementary Fig. S1) predicted in the TK motif of the $\beta$ subunit are identical to those in DAF- 2 orthologues in the free-living nematodes C. elegans and Caenorhabditis briggsae as well as clade III nematodes A. suum, B. malayi and $L$. loa, but different from those of the clade IVa nematodes $S$. stercoralis (see 
Massey et al., 2013, Fig. 2B), Strongyloides ratti and P. trichosuri. These two residues might be involved in interactions with insulin-like peptides (Kim et al., 1992) and/or with downstream signalling molecules (Hubbard, 1997).

\subsection{Evolutionary relationship of the predicted protein Hc-DAF-2 with DAF-2 orthologues from other species}

The predicted aa sequence of $\mathrm{Hc}$-DAF-2 was aligned with orthologues from nine nematodes and the same number of non-nematode species, and subjected to phylogenetic analyses (Fig. 3). There was concordance in topology between the MP and NJ trees. The four DAF-2 homologues from vertebrates included in the present study grouped together with strong nodal support (100\%), as did three insect and two molluscan DAF-2 homologues(95\% and $100 \%)$, respectively. If nematode sequences were excluded from the analysis, these invertebrate and vertebrate DAF-2 orthologues grouped together with strong support (99\%). All DAF-2 orthologues from nematodes grouped together with strong support (93\%). Specifically, Hc-DAF-2 grouped with DAF-2s of A. suum and two filarial worms (100\%), and with orthologues of $C$. elegans and $C$. briggsae (91\%) to the exclusion of those of $S$. stercoralis and P. trichosuri (Fig. 3).

\subsection{Characterisation of the genomic organisation of Hc-daf-2 and its putative promoter}

Using primers designed against cDNA sequence, eight overlapping fragments covering the entire $H c$-daf-2 gene were amplified from $H$. contortus genomic DNA, cloned and sequenced. The full-length $\mathrm{Hc}$-daf-2 gene sequence (from start codon to stop codon) is $15,003 \mathrm{bp}$ in length. The coding sequence comprises 37 exons of 39 to $177 \mathrm{bp}$ in length, and 36 introns of 51 to 1623 bp in length (Fig. 4 and Supplementary Table S2). All exon/intron boundaries, defined based on the alignment of the cDNA and genomic DNA sequences in Hc-daf-2, are consistent with the GT-AG rule (Breathnach and Chambon, 1981; Burset et al., 2000) (Supplementary Table S2). Thus, the full-length $H c$-daf-2 gene is more complex than those representing C. elegans (17 exons) (Kimura et al., 1997), S. stercoralis (two or three exons) (Massey et al., 2013), Echinococcus multilocularis (25 exons) (Konrad et al., 2003) and human (21 or 22 exons) (Ullrich et al., 1985; Bravo et al., 1994).

The promoter region of $H c-d a f-2$ is $3184 \mathrm{bp}$ in length. A sequence comparison revealed that the Hc-daf-2 promoter is $51 \%$ similar to that of Ce-daf-2 (Supplementary Fig. S2). A number of promoter elements, including six E-box motifs (CANNTG), 11 TATA boxes, nine CAAT (CCAAT) or inverse CAAT (ATTGG) and six inverse GATA (TTATC) motifs are predicted within the $\mathrm{Hc}$-daf-2 promoter. In addition, five forkhead box A (FoxA/HNF3) transcription factor PHA-4 binding sites (TRTTKRY) (Gaudet and Mango, 2002) are present in the $5^{\prime}$ flanking region of $\mathrm{Hc}$-daf-2. These elements likely represent activators of most or all genes expressed preferentially in the nematode pharynx (cf. Gaudet and Mango, 2002) (Supplementary Fig. S2). Most of these motifs are scattered across the promoter sequence, with no apparent pattern to their distribution.

\subsection{Transcriptional analysis of Hc-daf-2 in different developmental stages}

Transcription was explored in all key stages (i.e. eggs, L1s, L2s, iL3s, female L4s, male L4s, female adults and male adults) of the life cycle of $H$. contortus (cf. Schwarz et al., 2013). 
Hc-daf-2 transcripts were detected in all developmental stages of $H$. contortus (Fig. 5). Comparison of the FPKM (fragments per kilobase of coding exon per million mapped reads) values for $\mathrm{Hc}$-daf-2 allowed an estimate of changes in transcript abundance. While egg, iL3 and adult female stages had high transcription relative to other stages, iL3 exhibited the highest level of transcription overall (Fig. 5). Using tub-8-9 (the $\beta$-tubulin 8-9 gene) as a control gene, RT-PCR indicated that transcription was higher in the iL3 stage compared with other stages (data not shown).

\subsection{The expression pattern of the putative Hc-daf-2 promoter in transgenic C. elegans}

To investigate the anatomical expression pattern of $H c$-daf-2, wild type C. elegans were transformed with construct pL-HG2 (see Fig. 1) containing $3184 \mathrm{bp}$ of the predicted $\mathrm{Hc}$ $d a f-2$ promoter and a $g f p$ reporter gene (Hc-daf-2 p: :gfp) or with construct pL-CG2 (Fig. 1), which links the $C e-d a f-2$ promoter to $g f p$ as a control (Ce-daf-2 p: :gfp). Plasmid pRF4 was included in all transformations as a behavioural marker. The transgenic lines were screened based on the roller phenotype and GFP expression. For each construct, more than 50 parental hermaphrodites were transformed and their progeny founded four stable lines expressing the transgene. GFP expression driven by the Ce-daf-2 promoter was found predominantly in the intestine, amphidial/head neurons and elsewhere in the nervous system (Fig. 6). This pattern is consistent with previous reports (Dupuy et al., 2007; Hunt-Newbury et al., 2007; Kimura et al., 2011). Despite a varying intensity of GFP expression among different individuals, the four $H c-d a f-2 \mathrm{p}:: a f p$ transgenic lines showed similar expression patterns to the controls expressing Ce-daf-2 p: :gfp with the strongest signal in AWA (Amphid wing "A" cells) amphidial sensory neuron pairs (Fig. 6C and D). AWA amphidial neurons are important in relation to chemotaxis to volatile chemicals and lifespan regulation (Bargmann, 2006). In addition, GFP expression was observed in all stages including eggs, larvae and adults (data not shown).

\subsection{Attempts to complement a C. elegans daf-2 mutant strain with the $\mathbf{H}$. contortus daf-2 gene}

RT-PCR detected mRNA encoding the Hc-DAF-2 (Fig. 7A) in all lines of the daf-2 (e1370) mutant strain stably transformed with the pL-HD2 rescuing plasmid (Fig. 1) into daf-2 (e1370) mutant strain. Mutant rescue experiments revealed that the Ce-daf-2 transgene fully rescued the Ce-daf-2 (e1370) mutation (Fig. 7B). This temperature-sensitive mutation results in constitutive dauer development (Fig. 7C and D) in all worms cultured under wellfed conditions at $25{ }^{\circ} \mathrm{C}$. Worms expressing the Ce-daf-2 transgene developed through to reproductive hermaphrodites, suggesting that the regulatory sequences in our putative $\mathrm{Ce}$ daf-2 promoter can drive the expression of functional $\mathrm{Ce}$-DAF-2, thus providing a reliable basis for comparative studies of $\mathrm{Hc}$-DAF-2.

To determine the functional characteristics of the Hc-daf-2 gene, the rescuing construct containing the Ce-daf-2 promoter and the Hc-daf-2 coding sequence (pL-HD2, Fig. 1) was used to transform C. elegans daf-2 (e1370) mutants. Four transgenic lines were established and the dauer-switching assay was carried out. No non-dauer larvae or reproductive adults were observed in C elegans daf-2 (e1370) mutants transformed with Hc-daf-2. However, $\sim 26 \%$ of the larvae (which we called partial dauer) exhibited some non-dauer characteristics 
such as resumed pharyngeal pumping and reversal of radial constriction of the body, enlargement of the pharyngeal bulb and elongation of the gonad (Fig. 7). The results of comparisons of ratio of the body length to the body width, the gonad length and the cross sectional area of pharyngeal bulb between dauer and partial dauer are also shown in Fig. 7 (Fig. 7G-I). Percentages of non-dauer, dauer and partial dauer larvae in populations of C elegans daf-2 (e1370) mutants transformed with rescuing constructs encoding either $\mathrm{Ce}$ daf- 2 or Hc-daf-2 appear in Fig. 7J, together with percentages in these same developmental classes in populations of non-transformed C elegans daf-2 (e1370) mutants and nontransformed wild type (N2) C. elegans. $\chi^{2}$ analysis revealed highly significant $(P \leq 0.0001)$ differences in proportions of non-dauer, dauer and partial dauer development in these four populations.

\section{Discussion}

Signalling by the insulin/IGF-1-like kinase DAF-2 is an important regulator of the transition between dauer and continuous larval development in C. elegans (see Kimura et al., 1997). The insulinlike signalling pathway is relatively conserved from cnidarians to chordates, and its insulin-like hormones and receptors as well as signalling kinases function in intercellular communication (Konrad et al., 2003). In recent years, components of the insulinlike signalling pathway have been isolated from parasitic nematodes including A. caninum (see Gao et al., 2009; Gelmedin et al., 2011), H. contortus (see Hu et al., 2010) and S. stercoralis (see Massey et al., 2003, 2006, 2013), indicating that parasitic nematodes such as $H$. contortus utilise similar signalling. In the present study, a single gene of $\mathrm{Hc}$-daf-2 was found in $H$. contortus by searching public data sets (Laing et al., 2013; Schwarz et al., 2013). This finding is relatively consistent with some invertebrates such as $C$. elegans and $D$. melanogaster (see Ruan et al., 1995; Kimura et al., 1997), which have one gene in contrast to humans and other vertebrates which can contain up to three different paralogues representing this receptor family (White and Kahn, 1994; Pashmforoush et al., 1996). Although S. stercoralis is predicted to have two alternately spliced isoforms of $d a f-2$ (Massey et al., 2013), our searches of transcriptomic databases indicate that most nematodes, including C. briggsae, A. suum, B. malayi and L. loa, transcribe only one daf-2 isoform.

Sequence and structural analyses revealed that $\mathrm{Hc}$-DAF-2 has the conserved structural features representative of kinases in the insulin-like receptor family, including L1-CR-L2 and TK domains, separated by FN domains. Interestingly, in accordance with the proteolytic motifs RKRR of human IR (HIR), which are essential for processing of the HIR by furin endoproteases (Sparrow et al., 1997), the presence of an identical tetrabasic motif in $\mathrm{Hc}$ DAF-2 suggests that it is involved in the formation of the $\alpha_{2} \beta_{2}$ IR complex in H. contortus. The a subunit of $\mathrm{Hc}$-DAF-2 contains a cysteine-rich cluster in the CR region, similar to that of the epidermal growth factor (EGF) receptor kinase (Downward et al., 1984; Ullrich et al., 1985), and in the ligand binding domain of the low-density lipoprotein (LDL) receptor (Yamamoto et al., 1984). Each a subunit of the tetrameric IR might contribute a CR region, to constitute an analogous functional domain. The $\beta$ subunit of $H c$-DAF- 2 contains a clearly recognisable 24-residue transmembrane segment, which is analogous to that of EGF and LDL receptors and an ATP binding site that could anchor the insulin-like receptor in the 
membrane and contribute to its protein kinase activity. In addition, $H c$-DAF-2 also has a classical NPXY-docking site in the juxta-membrane region for IR substrate (IRS) and of the SH2 domain-containing protein (SHC) adaptor protein. Moreover, the presence of an autophosphorylation motif (YXXXYY), which is essential for the function of the TK domains of insulin-like receptors, usually implies an important regulatory role during signal transduction. Mutations of 1, 2 or 3 tyrosine residues in this motif lead to a progressive reduction of insulin-stimulated kinase activity and a parallel loss of biological activity in mammals (Vogt et al., 1991; Wilden et al., 1992). The presence of all of these conserved insulin-receptor domains in $\mathrm{Hc}$-DAF-2 suggests that similar insulin-like signalling operates in $H$. contortus.

During dauer switching in C. elegans, many genes including insulin-like peptides (ILPs) and Ce-daf-7 (a TGF- $\beta$ ligand) are transcriptionally regulated. To gain insight into the roles of $\mathrm{Hc}$-daf-2, transcript abundance was examined in eight different developmental stages. $\mathrm{Hc}$ $d a f-2$ transcripts are present throughout the entire life cycle, but are significantly upregulated in the iL3 stage. This upregulation might relate directly to developmental arrest, in preparation for further reproductive development, and is consistent with the transcription profiles for Ss-daf-2b, Ss-age-1, Ss-pdk-1 and Ss-akt-1 in S. stercoralis (see Stoltzfus et al., 2012b; Massey et al., 2013). This information indicates that the insulin-like receptor encoded by $\mathrm{Hc}$-daf-2 plays a crucial role in the transition from a developmentally arrested to an activated state in $H$. contortus.

The expression of $H c$-daf-2 is localised to amphidial neurons in all larval stages of $C$. elegans, which is consistent with the expression of the Ce-daf-2 promoter and results from high-throughput in vivo analyses of $C$. elegans (see WormAtlas; http:// gfpweb.aecom.yu.edu/strain?name=BC14074), where the expression of Ce-daf-2 promoter: : $g f p$ fusion constructs occurs in intestine, amphidial/head neurons and other parts of the nervous system. It is an intriguing proposition that some agonistic peptides produced by head neurons (Bargmann and Horvitz, 1991; Schackwitz et al., 1996; Wes and Bargmann, 2001; Cornils et al., 2011) could play a critical role in regulating the entry into, and exit from, dauer. The expression profile might not only identify spatiotemporal territories of the promoter, but also hint at functional characteristics, including the proteinprotein interactome (Dupuy et al., 2007). Thus, the similarity of the anatomical expression pattern of $\mathrm{Hc}$-daf-2 to that of Ce-daf-2 in amphidial/head neurons suggests that the putative promoter of $\mathrm{Hc}-d a f-2$ has similar gene regulatory activity to the promoter of $\mathrm{Ce}-\mathrm{daf}-2$.

The conservation of functional domains between $\mathrm{Hc}$-DAF-2 and $\mathrm{Ce}$-DAF-2 suggests that $H c-d a f-2$ is a functional orthologue of $\mathrm{Ce}$-daf-2, and could bind insulin-like peptides and regulate the IIS pathway. To test this hypothesis, heterologous genetic complementation was assessed here in C. elegans. Although the $d a f-2$ (e1370) mutation was fully rescued by the $C e$-daf-2 construct, indicating that the Ce-daf-2 coding sequence and regulatory regions can direct appropriate expression and interact with ligands and downstream signalling in the transgenic worms, this mutation was only partially rescued by the Hc-daf-2 transgene. Interestingly, the partially rescued worms exhibited resumed and/or other non-dauer characteristics, which might suggest that $\mathrm{Hc}$-DAF-2 can direct similar functions in the parasite itself. 
In parasitic nematodes, the resumption of feeding has been used as a phenotypic marker in an in vitro activation assay (Hawdon et al., 1993; Brand and Hawdon, 2004; Cantacessi et al., 2010; Huang et al., 2010; Stoltzfus et al., 2012a), and the PI3 kinase inhibitor LY294002 effectively blocks resumption of feeding (Brand and Hawdon, 2004; Stoltzfus et al., 2012a). This phenomenon suggests that the IIS pathway might be conserved and regulates the activation of iL3 in strongylid nematodes. The failure of a Hc-daf-2 transgene to fully rescue the Ce-daf-2 mutation might be due to an inability of the parasite's insulin-like receptor to assemble in $\alpha_{2} \beta_{2}$ heterotetramers, owing to the presence of eight consensus sequences for $\mathrm{N}$ linked glycosylation (Bass et al., 1998). Alternatively, heterologous insulin-like receptors might require different molecular chaperones, such as $\mathrm{Cnx}$ and $\mathrm{Crt}$, which could provide protection to exposed hydrophobic domains and prevent their mis-folding and aggregation, to enable them to attain their native conformation (Hebert et al., 1996; Vassilakos et al., 1996). Thus, the resultant immature insulin-like receptor might contribute only partial function to C. elegans transformed with a parasite orthologue. In C. elegans, there are 40 insulin-like peptides, many of which are thought to play crucial roles in regulating dauer entry versus exit as well as other aspects of development and lifespan (Pierce et al., 2001; Li et al., 2003; Baugh et al., 2011; Cornils et al., 2011). By contrast, parasitic nematodes studied to date appear to have much-reduced repertoires of insulin-like peptides (Stoltzfus et al., 2012b). The unsuitable interaction between ligands and IR may also have led to compromised function and, therefore, incomplete rescue.

The 'dauer hypothesis' holds that similar signal transduction mechanisms regulate dauer development in C. elegans and the development of iL3 in some parasitic nematodes. Heterologous complementation in C. elegans was attempted to assess functional capabilities of $H c-d a f-2$, because transgenesis has not yet been achieved in H. contortus. Research on this and other parasitic nematodes supports that the main components of the insulin-like signalling pathway, such as daf-16 and age-1 (Massey et al., 2003; Castelletto et al., 2009; Gao et al., 2009; Hu et al., 2010; Stoltzfus et al., 2012a), function similarly to their orthologues in C. elegans. The present study of an insulin-like receptor gene of $H$. contortus has not only shown functional similarities to the orthologue in C. elegans, but also significant areas of divergence. This statement underscores that comparative analysis and careful experimental interpretation are critical (cf. Gilleard, 2004). The recent achievement of heritable transgenesis in S. ratti, mediated by the piggyBac transposon (Shao et al., 2012), could provide an experimental platform to demonstrate the function of putative regulatory genes in parasitic nematodes of animals.

In conclusion, in the present study we investigated an insulinlike receptor-encoding gene, $H c$-daf-2, in the parasitic nematode $H$. contortus. We characterised the cDNA, genomic DNA and promoter region of $\mathrm{Hc}$-daf-2, and ascertained its transcriptional profile in all key developmental stages. We also confirmed the functional characteristics of $d a f-2$ between $H$. contortus and C. elegans by the gene expression localisation and heterologous gene rescue. Taken together, the present findings provide first, important insights into developmental processes in strongylid nematodes, particularly in the transition to parasitism. 


\section{Supplementary Material}

Refer to Web version on PubMed Central for supplementary material.

\section{Acknowledgments}

This study was supported by "National Natural Science Foundation of China (NSFC)" (Grant No. 31172310), the "Fundamental Research Funds for the Central Universities", China (Program No. 2011PY118) and "Special Fund for Agro-scientific Research in the Public Interest", China (Grant No. 201303037) to MH and by a grant from The National Institutes of Health (NIH), USA (AI-50688) to JBL. Funding from the National Health and Medical Research Council (NHMRC) of Australia, the Australian Research Council (ARC) and Melbourne Water Corporation, Australia is gratefully acknowledged (RBG). This study was also supported by a Victorian Life Sciences Computation Initiative (VLSCI), Australia, grant number VR0007 on its Peak Computing Facility at the University of Melbourne, an initiative of the Victorian Government, Australia (RBG). Other support from the Australian Academy of Science and the Alexander von Humboldt Foundation, Germany is gratefully acknowledged (RBG).

\section{References}

Aboobaker AA, Blaxter ML. Functional genomics for parasitic nematodes and platyhelminths. Trends Parasitol. 2004; 20:178-184. [PubMed: 15099557]

Apfeld J, Kenyon C. Cell nonautonomy of C. elegans daf-2 function in the regulation of diapause and life span. Cell. 1998; 95:199-210. [PubMed: 9790527]

Ayyadevara S, Tazearslan C, Bharill P, Alla R, Siegel E, Shmookler Reis RJ. Caenorhabditis elegans PI3K mutants reveal novel genes underlying exceptional stress resistance and lifespan. Aging Cell. 2009; 8:706-725. [PubMed: 19764929]

Bargmann, CI. WormBook., editor. Chemosensation in C. elegans. The C elegans Research Community. 2006. Available from: <http://www.wormbook.org/chapters/www_chemosensation/ chemosensation.html>

Bargmann CI, Horvitz HR. Chemosensory neurons with overlapping functions direct chemotaxis to multiple chemicals in C. elegans. Neuron. 1991; 7:729-742. [PubMed: 1660283]

Bass J, Chiu G, Argon Y, Steiner DF. Folding of insulin receptor monomers is facilitated by the molecular chaperones calnexin and calreticulin and impaired by rapid dimerization. J Cell Biol. 1998; 141:637-646. [PubMed: 9566965]

Baugh LR, Kurhanewicz N, Sternberg PW. Sensitive and precise quantification of insulin-like mRNA expression in Caenorhabditis elegans. PLoS One. 2011; 6:e18086. [PubMed: 21445366]

Blaxter M. Caenorhabditis elegans is a nematode. Science. 1998; 282:2041-2046. [PubMed: 9851921]

Blaxter ML, De Ley P, Garey JR, Liu LX, Scheldeman P, Vierstraete A, Vanfleteren JR, Mackey LY, Dorris M, Frisse LM, Vida JT, Thomas WK. A molecular evolutionary framework for the phylum Nematoda. Nature. 1998; 392:71-75. [PubMed: 9510248]

Blaxter ML, Raghavan N, Ghosh I, Guiliano D, Lu W, Williams SA, Slatko B, Scott AL. Genes expressed in Brugia malayi infective third stage larvae. Mol Biochem Parasitol. 1996; 77:77-93. [PubMed: 8784774]

Boyle JP, Yoshino TP. Gene manipulation in parasitic helminths. Int J Parasitol. 2003; 33:1259-1268. [PubMed: 13678640]

Brand A, Hawdon JM. Phosphoinositide-3-OH-kinase inhibitor LY294002 prevents activation of Ancylostoma caninum and Ancylostoma ceylanicum third-stage infective larvae. Int J Parasitol. 2004; 34:909-914. [PubMed: 15217729]

Bravo DA, Gleason JB, Sanchez RI, Roth RA, Fuller RS. Accurate and efficient cleavage of the human insulin proreceptor by the human proprotein-processing protease furin. Characterization and kinetic parameters using the purified, secreted soluble protease expressed by a recombinant baculovirus. J Biol Chem. 1994; 269:25830-25837. [PubMed: 7929288]

Breathnach R, Chambon P. Organization and expression of eucaryotic split genes coding for proteins. Annu Rev Biochem. 1981; 50:349-383. [PubMed: 6791577] 
Britton C, Murray L. Using Caenorhabditis elegans for functional analysis of genes of parasitic nematodes. Int J Parasitol. 2006; 36:651-659. [PubMed: 16616144]

Bürglin TR, Lobos E, Blaxter ML. Caenorhabditis elegans as a model for parasitic nematodes. Int J Parasitol. 1998; 28:395-411. [PubMed: 9559358]

Burset M, Seledtsov IA, Solovyev VV. Analysis of canonical and non-canonical splice sites in mammalian genomes. Nucleic Acids Res. 2000; 28:4364-4375. [PubMed: 11058137]

Cantacessi C, Campbell BE, Young ND, Jex AR, Hall RS, Presidente PJ, Zawadzki JL, Zhong W, Aleman-Meza B, Loukas A, Sternberg PW, Gasser RB. Differences in transcription between freeliving and $\mathrm{CO}_{2}$-activated third-stage larvae of Haemonchus contortus. BMC Genomics. 2010; 11:266. [PubMed: 20420710]

Castelletto ML, Massey HC Jr, Lok JB. Morphogenesis of Strongyloides stercoralis infective larvae requires the DAF-16 ortholog FKTF-1. PLoS Pathog. 2009; 5:e1000370. [PubMed: 19360119]

Cornils A, Gloeck M, Chen Z, Zhang Y, Alcedo J. Specific insulin-like peptides encode sensory information to regulate distinct developmental processes. Development. 2011; 138:1183-1193. [PubMed: 21343369]

Cox DD, Todd AC. Survey of gastrointestinal parasitism in Wisconsin dairy cattle. J Am Vet Med Assoc. 1962; 141:706-709. [PubMed: 13881890]

Crompton DW. How much human helminthiasis is there in the world? J Parasitol. 1999; 85:397-403. [PubMed: 10386428]

Crook M, Grant K, Grant WN. Failure of Parastrongyloides trichosuri daf-7 to complement a Caenorhabditis elegans daf-7 (e1372) mutant: implications for the evolution of parasitism. Int J Parasitol. 2010; 40:1675-1683. [PubMed: 20673766]

Desjardins CA, Cerqueira GC, Goldberg JM, Dunning Hotopp JC, Haas BJ, Zucker J, Ribeiro JM, Saif S, Levin JZ, Fan L, Zeng Q, Russ C, Wortman JR, Fink DL, Birren BW, Nutman TB. Genomics of Loa loa, a Wolbachia-free filarial parasite of humans. Nat Genet. 2013; 45:495-500. [PubMed: 23525074]

Downward J, Yarden Y, Mayes E, Scrace G, Totty N, Stockwell P, Ullrich A, Schlessinger J, Waterfield MD. Close similarity of epidermal growth factor receptor and v-erb-B oncogene protein sequences. Nature. 1984; 307:521-527. [PubMed: 6320011]

Dupuy D, Bertin N, Hidalgo CA, Venkatesan K, Tu D, Lee D, Rosenberg J, Svrzikapa N, Blanc A, Carnec A, Carvunis AR, Pulak R, Shingles J, Reece-Hoyes J, Hunt-Newbury R, Viveiros R, Mohler WA, Tasan M, Roth FP, Le Peuch C, Hope IA, Johnsen R, Moerman DG, Barabasi AL, Baillie D, Vidal M. Genome-scale analysis of in vivo spatiotemporal promoter activity in Caenorhabditis elegans. Nat Biotechnol. 2007; 25:663-668. [PubMed: 17486083]

Engelman JA, Luo J, Cantley LC. The evolution of phosphatidylinositol 3-kinases as regulators of growth and metabolism. Nat Rev Genet. 2006; 7:606-619. [PubMed: 16847462]

Gao X, Frank D, Hawdon JM. Molecular cloning and DNA binding characterization of DAF-16 orthologs from Ancylostoma hookworms. Int J Parasitol. 2009; 39:407-415. [PubMed: 18930062]

Gaudet J, Mango SE. Regulation of organogenesis by the Caenorhabditis elegans FoxA protein PHA-4. Science. 2002; 295:821-825. [PubMed: 11823633]

Geary TG, Woo K, McCarthy JS, Mackenzie CD, Horton J, Prichard RK, de Silva NR, Olliaro PL, Lazdins-Helds JK, Engels DA, Bundy DA. Unresolved issues in anthelmintic pharmacology for helminthiases of humans. Int J Parasitol. 2010; 40:1-13. [PubMed: 19932111]

Gelmedin V, Brodigan T, Gao X, Krause M, Wang Z, Hawdon JM. Transgenic C. elegans dauer larvae expressing hookworm phospho null DAF-16/FoxO exit dauer. PLoS One. 2011; 6:e25996. [PubMed: 22016799]

Gems D, Sutton AJ, Sundermeyer ML, Albert PS, King KV, Edgley ML, Larsen PL, Riddle DL. Two pleiotropic classes of $d a f-2$ mutation affect larval arrest, adult behavior, reproduction and longevity in Caenorhabditis elegans. Genetics. 1998; 150:129-155. [PubMed: 9725835]

Ghedin E, Wang S, Spiro D, Caler E, Zhao Q, Crabtree J, Allen JE, Delcher AL, Guiliano DB, Miranda-Saavedra D, Angiuoli SV, Creasy T, Amedeo P, Haas B, El-Sayed NM, Wortman JR, Feldblyum T, Tallon L, Schatz M, Shumway M, Koo H, Salzberg SL, Schobel S, Pertea M, Pop M, White O, Barton GJ, Carlow CK, Crawford MJ, Daub J, Dimmic MW, Estes CF, Foster JM, Ganatra M, Gregory WF, Johnson NM, Jin J, Komuniecki R, Korf I, Kumar S, Laney S, Li BW, 
Li W, Lindblom TH, Lustigman S, Ma D, Maina CV, Martin DM, McCarter JP, McReynolds L, Mitreva M, Nutman TB, Parkinson J, Peregrin-Alvarez JM, Poole C, Ren Q, Saunders L, Sluder AE, Smith K, Stanke M, Unnasch TR, Ware J, Wei AD, Weil G, Williams DJ, Zhang Y, Williams SA, Fraser-Liggett C, Slatko B, Blaxter ML, Scott AL. Draft genome of the filarial nematode parasite Brugia malayi. Science. 2007; 317:1756-1760. [PubMed: 17885136]

Gilleard JS. The use of Caenorhabditis elegans in parasitic nematode research. Parasitology. 2004; 128(Suppl 1):S49-S70. [PubMed: 16454899]

Gilleard JS, Beech RN. Population genetics of anthelmintic resistance in parasitic nematodes. Parasitology. 2007; 134:1133-1147. [PubMed: 17608973]

Godel C, Kumar S, Koutsovoulos G, Ludin P, Nilsson D, Comandatore F, Wrobel N, Thompson M, Schmid CD, Goto S, Bringaud F, Wolstenholme A, Bandi C, Epe C, Kaminsky R, Blaxter M, Maser P. The genome of the heartworm, Dirofilaria immitis, reveals drug and vaccine targets. FASEB J. 2012; 26:4650-4661. [PubMed: 22889830]

Golden JW, Riddle DL. The Caenorhabditis elegans dauer larva: developmental effects of pheromone, food, and temperature. Dev Biol. 1984; 102:368-378. [PubMed: 6706004]

Gustafson TA, He W, Craparo A, Schaub CD, O'Neill TJ. Phosphotyrosine-dependent interaction of SHC and insulin receptor substrate 1 with the NPEY motif of the insulin receptor via a novel nonSH2 domain. Mol Cell Biol. 1995; 15:2500-2508. [PubMed: 7537849]

Hanks SK, Hunter T. Protein kinases 6. The eukaryotic protein kinase superfamily: kinase (catalytic) domain structure and classification. FASEB J. 1995; 9:576-596. [PubMed: 7768349]

Hashmi S, Tawe W, Lustigman S. Caenorhabditis elegans and the study of gene function in parasites. Trends Parasitol. 2001; 17:387-393. [PubMed: 11685900]

Hawdon JM, Volk SW, Rose R, Pritchard DI, Behnke JM, Schad GA. Observations on the feeding behaviour of parasitic third-stage hookworm larvae. Parasitology. 1993; 106(Pt 2):163-169. [PubMed: 8446471]

Hebert DN, Foellmer B, Helenius A. Calnexin and calreticulin promote folding, delay oligomerization and suppress degradation of influenza hemagglutinin in microsomes. EMBO J. 1996; 15:29612968. [PubMed: 8670797]

Hotez P, Hawdon J, Schad GA. Hookworm larval infectivity, arrest and amphiparatenesis: the Caenorhabditis elegans Daf-c paradigm. Parasitol Today. 1993; 9:23-26. [PubMed: 15463660]

Hotez PJ, Fenwick A, Savioli L, Molyneux DH. Rescuing the bottom billion through control of neglected tropical diseases. Lancet. 2009; 373:1570-1575. [PubMed: 19410718]

Hu M, Lok JB, Ranjit N, Massey HC Jr, Sternberg PW, Gasser RB. Structural and functional characterisation of the fork head transcription factor-encoding gene, $\mathrm{Hc}$-daf-16, from the parasitic nematode Haemonchus contortus (Strongylida). Int J Parasitol. 2010; 40:405-415. [PubMed: 19796644]

Hu, PJ. WormBook. , editor. Dauer. The C elegans Research Community. 2007. Available from: <http://www.wormbook.org/chapters/www_dauer/dauer.html>

Huang SC, Chan DT, Smyth DJ, Ball G, Gounaris K, Selkirk ME. Activation of Nippostrongylus brasiliensis infective larvae is regulated by a pathway distinct from the hookworm Ancylostoma caninum. Int J Parasitol. 2010; 40:1619-1628. [PubMed: 20654619]

Hubbard SR. Crystal structure of the activated insulin receptor tyrosine kinase in complex with peptide substrate and ATP analog. EMBO J. 1997; 16:5572-5581. [PubMed: 9312016]

Hunt-Newbury R, Viveiros R, Johnsen R, Mah A, Anastas D, Fang L, Halfnight E, Lee D, Lin J, Lorch A, McKay S, Okada HM, Pan J, Schulz AK, Tu D, Wong K, Zhao Z, Alexeyenko A, Bürglin T, Sonnhammer E, Schnabel R, Jones SJ, Marra MA, Baillie DL, Moerman DG. Highthroughput in vivo analysis of gene expression in Caenorhabditis elegans. PLoS Biol. 2007; 5:e237. [PubMed: 17850180]

Jex AR, Liu S, Li B, Young ND, Hall RS, Li Y, Yang L, Zeng N, Xu X, Xiong Z, Chen F, Wu X, Zhang G, Fang X, Kang Y, Anderson GA, Harris TW, Campbell BE, Vlaminck J, Wang T, Cantacessi C, Schwarz EM, Ranganathan S, Geldhof P, Nejsum P, Sternberg PW, Yang H, Wang J, Gasser RB. Ascaris suum draft genome. Nature. 2011; 479:529-533. [PubMed: 22031327]

Kalinna BH, Brindley PJ. Manipulating the manipulators: advances in parasitic helminth transgenesis and RNAi. Trends Parasitol. 2007; 23:197-204. [PubMed: 17383233] 
Kaplan RM. Drug resistance in nematodes of veterinary importance. a status report. Trends Parasitol. 2004; 20:477-481. [PubMed: 15363441]

Kim H, Kadowaki H, Sakura H, Odawara M, Momomura K, Takahashi Y, Miyazaki Y, Ohtani T, Akanuma Y, Yazaki Y, Kasaga M, Taylor SI, Kadowaki T. Detection of mutations in the insulin receptor gene in patients with insulin resistance by analysis of single-stranded conformational polymorphisms. Diabetologia. 1992; 35:261-266. [PubMed: 1563582]

Kimura KD, Riddle DL, Ruvkun G. The C. elegans DAF-2 insulin-like receptor is abundantly expressed in the nervous system and regulated by nutritional status. Cold Spring Harb Symp Quant Biol. 2011; 76:113-120. [PubMed: 22123849]

Kimura KD, Tissenbaum HA, Liu Y, Ruvkun G. daf-2, an insulin receptorlike gene that regulates longevity and diapause in Caenorhabditis elegans. Science. 1997; 277:942-946. [PubMed: 9252323]

Knox DP, Geldhof P, Visser A, Britton C. RNA interference in parasitic nematodes of animals: a reality check? Trends Parasitol. 2007; 23:105-107. [PubMed: 17276139]

Konrad C, Kroner A, Spiliotis M, Zavala-Gongora R, Brehm K. Identification and molecular characterisation of a gene encoding a member of the insulin receptor family in Echinococcus multilocularis. Int J Parasitol. 2003; 33:301-312. [PubMed: 12670515]

Laing R, Kikuchi T, Martinelli A, Tsai IJ, Beech RN, Redman E, Holroyd N, Bartley DJ, Beasley H, Britton C, Curran D, Devaney E, Gilabert A, Hunt M, Jackson F, Johnston SL, Kryukov I, Li K, Morrison AA, Reid AJ, Sargison N, Saunders GI, Wasmuth JD, Wolstenholme A, Berriman M, Gilleard JS, Cotton JA. The genome and transcriptome of Haemonchus contortus, a key model parasite for drug and vaccine discovery. Genome Biol. 2013; 14:R88. [PubMed: 23985316]

Li W, Kennedy SG, Ruvkun G. daf-28 encodes a C. elegans insulin superfamily member that is regulated by environmental cues and acts in the DAF-2 signaling pathway. Genes Dev. 2003; 17:844-858. [PubMed: 12654727]

Lin K, Dorman JB, Rodan A, Kenyon C. daf-16: an HNF-3/forkhead family member that can function to double the life-span of Caenorhabditis elegans. Science. 1997; 278:1319-1322. [PubMed: 9360933]

Lizotte-Waniewski M, Tawe W, Guiliano DB, Lu W, Liu J, Williams SA, Lustigman S. Identification of potential vaccine and drug target candidates by expressed sequence tag analysis and immunoscreening of Onchocerca volvulus larval cDNA libraries. Infect Immun. 2000; 68:34913501. [PubMed: 10816503]

Massey HC Jr, Bhopale MK, Li X, Castelletto M, Lok JB. The fork head transcription factor FKTF-1b from Strongyloides stercoralis restores DAF-16 developmental function to mutant Caenorhabditis elegans. Int J Parasitol. 2006; 36:347-352. [PubMed: 16442538]

Massey HC Jr, Nishi M, Chaudhary K, Pakpour N, Lok JB. Structure and developmental expression of Strongyloides stercoralis fktf-1, a proposed ortholog of daf-16 in Caenorhabditis elegans. Int J Parasitol. 2003; 33:1537-1544. [PubMed: 14572516]

Massey HC Jr, Ranjit N, Stoltzfus JD, Lok JB. Strongyloides stercoralis daf-2 encodes a divergent ortholog of Caenorhabditis elegans DAF-2. Int J Parasitol. 2013; 43:515-520. [PubMed: 23500073]

Maule AG, McVeigh P, Dalzell JJ, Atkinson L, Mousley A, Marks NJ. An eye on RNAi in nematode parasites. Trends Parasitol. 2011; 27:505-513. [PubMed: 21885343]

Mello CC, Kramer JM, Stinchcomb D, Ambros V. Efficient gene transfer in C. elegans: extrachromosomal maintenance and integration of transforming sequences. EMBO J. 1991; 10:3959-3970. [PubMed: 1935914]

Mortazavi A, Schwarz EM, Williams B, Schaeffer L, Antoshechkin I, Wold BJ, Sternberg PW. Scaffolding a Caenorhabditis nematode genome with RNA-seq. Genome Res. 2010; 20:1740 1747. [PubMed: 20980554]

Mukhopadhyay A, Oh SW, Tissenbaum HA. Worming pathways to and from DAF-16/FOXO. Exp Gerontol. 2006; 41:928-934. [PubMed: 16839734]

Nelson MD, Fitch DH. Overlap extension PCR: an efficient method for transgene construction. Methods Mol Biol. 2011; 772:459-470. [PubMed: 22065455] 
Nielsen H, Engelbrecht J, Brunak S, von Heijne G. A neural network method for identification of prokaryotic and eukaryotic signal peptides and prediction of their cleavage sites. Int J Neural Syst. 1997; 8:581-599. [PubMed: 10065837]

Nolan KM, Sarafi-Reinach TR, Horne JG, Saffer AM, Sengupta P. The DAF-7 TGF-beta signaling pathway regulates chemosensory receptor gene expression in C. elegans. Genes Dev. 2002; 16:3061-3073. [PubMed: 12464635]

Ogg S, Paradis S, Gottlieb S, Patterson GI, Lee L, Tissenbaum HA, Ruvkun G. The Fork head transcription factor DAF-16 transduces insulin-like metabolic and longevity signals in C. elegans. Nature. 1997; 389:994-999. [PubMed: 9353126]

Ogg S, Ruvkun G. The C. elegans PTEN homolog, DAF-18, acts in the insulin receptor-like metabolic signaling pathway. Mol Cell. 1998; 2:887-893. [PubMed: 9885576]

Papadopoulos E, Gallidis E, Ptochos S. Anthelmintic resistance in sheep in Europe: a selected review. Vet Parasitol. 2012; 189:85-88. [PubMed: 22503039]

Pashmforoush M, Chan SJ, Steiner DF. Structure and expression of the insulin-like peptide receptor from amphioxus. Mol Endocrinol. 1996; 10:857-866. [PubMed: 8813726]

Pierce SB, Costa M, Wisotzkey R, Devadhar S, Homburger SA, Buchman AR, Ferguson KC, Heller J, Platt DM, Pasquinelli AA, Liu LX, Doberstein SK, Ruvkun G. Regulation of DAF-2 receptor signaling by human insulin and ins-1, a member of the unusually large and diverse $C$. elegans insulin gene family. Genes Dev. 2001; 15:672-686. [PubMed: 11274053]

Riddle, DL.; Albert, PS. Genetic and environmental regulation of dauer larva development. Riddle, DL.; elegans, C., II, editors. Cold Spring Harbor Press; Plainview, NY: 1997. p. 739-768.

Ruan Y, Chen C, Cao Y, Garofalo RS. The Drosophila insulin receptor contains a novel carboxylterminal extension likely to play an important role in signal transduction. J Biol Chem. 1995; 270:4236-4243. [PubMed: 7876183]

Schackwitz WS, Inoue T, Thomas JH. Chemosensory neurons function in parallel to mediate a pheromone response in C. elegans. Neuron. 1996; 17:719-728. [PubMed: 8893028]

Schnyder M, Torgerson PR, Schonmann M, Kohler L, Hertzberg H. Multiple anthelmintic resistance in Haemonchus contortus isolated from South African Boer goats in Switzerland. Vet Parasitol. 2005; 128:285-290. [PubMed: 15740865]

Schwarz EM, Korhonen PK, Campbell BE, Young ND, Jex AR, Jabbar A, Hall RS, Mondal A, Howe AC, Pell J, Hofmann A, Boag PR, Zhu XQ, Gregory TR, Loukas A, Williams BA, Antoshechkin I, Brown CT, Sternberg PW, Gasser. The genome and developmental transcriptome of the strongylid nematode Haemonchus contortus. Genome Biol. 2011; 14:R89. [PubMed: 23985341]

Shao H, Li X, Nolan TJ, Massey HC Jr, Pearce EJ, Lok JB. Transposon-mediated chromosomal integration of transgenes in the parasitic nematode Strongyloides ratti and establishment of stable transgenic lines. PLoS Pathog. 2012; 8:e1002871. [PubMed: 22912584]

Sparrow LG, McKern NM, Gorman JJ, Strike PM, Robinson CP, Bentley JD, Ward CW. The disulfide bonds in the C-terminal domains of the human insulin receptor ectodomain. J Biol Chem. 1997; 272:29460-29467. [PubMed: 9368005]

Stiernagle, T. WormBook. , editor. Maintenance of C. elegans. The C elegans Reasearch Community. 2006. Available from <http://www.wormbook.org/chapters/www_strainmaintain/ strainmaintain.html>

Stoltzfus JD, Massey HC Jr, Nolan TJ, Griffith SD, Lok JB. Strongyloides stercoralis age-1: a potential regulator of infective larval development in a parasitic nematode. PLoS One. 2012a; 7:e38587. [PubMed: 22701676]

Stoltzfus JD, Minot S, Berriman M, Nolan TJ, Lok JB. RNAseq analysis of the parasitic nematode Strongyloides stercoralis reveals divergent regulation of canonical dauer pathways. PLoS Negl Trop Dis. 2012b; 6:e1854. [PubMed: 23145190]

Tang YT, Gao X, Rosa BA, Abubucker S, Hallsworth-Pepin K, Martin J, Tyagi R, Heizer E, Zhang X, Bhonagiri-Palsikar V, Minx P, Warren WC, Wang Q, Zhan B, Hotez PJ, Sternberg PW, Dougall A, Gaze ST, Mulvenna J, Sotillo J, Ranganathan S, Rabelo EM, Wilson RK, Felgner PL, Bethony J, Hawdon JM, Gasser RB, Loukas A, Mitreva M. Genome of the human hookworm Necator americanus. Nat Genet. 2014; 46:261-269. [PubMed: 24441737] 
Tamura K, Peterson D, Peterson N, Stecher G, Nei M, Kumar S. MEGA5: molecular evolutionary genetics analysis using maximum likelihood, evolutionary distance, and maximum parsimony methods. Mol Biol Evol. 2011; 28:2731-2739. [PubMed: 21546353]

Thompson JD, Higgins DG, Gibson TJ. CLUSTAL W: improving the sensitivity of progressive multiple sequence alignment through sequence weighting, position-specific gap penalties and weight matrix choice. Nucleic Acids Res. 1994; 22:4673-4680. [PubMed: 7984417]

Ullrich A, Bell JR, Chen EY, Herrera R, Petruzzelli LM, Dull TJ, Gray A, Coussens L, Liao YC, Tsubokawa M, et al. Human insulin receptor and its relationship to the tyrosine kinase family of oncogenes. Nature. 1985; 313:756-761. [PubMed: 2983222]

Vanhaesebroeck B, Leevers SJ, Panayotou G, Waterfield MD. Phosphoinositide 3-kinases: a conserved family of signal transducers. Trends Biochem Sci. 1997; 22:267-272. [PubMed: 9255069]

Vassilakos A, Cohen-Doyle MF, Peterson PA, Jackson MR, Williams DB. The molecular chaperone calnexin facilitates folding and assembly of class I histocompatibility molecules. EMBO J. 1996; 15:1495-1506. [PubMed: 8612572]

Vogt B, Carrascosa JM, Ermel B, Ullrich A, Haring HU. The two isotypes of the human insulin receptor (HIR-A and HIR-B) follow different internalization kinetics. Biochem Biophys Res Commun. 1991; 177:1013-1018. [PubMed: 1647764]

Wes PD, Bargmann CI. C. elegans odour discrimination requires asymmetric diversity in olfactory neurons. Nature. 2001; 410:698-701. [PubMed: 11287957]

White MF, Kahn CR. The insulin signaling system. J Biol Chem. 1994; 269:1-4. [PubMed: 8276779]

White MF, Livingston JN, Backer JM, Lauris V, Dull TJ, Ullrich A, Kahn CR. Mutation of the insulin receptor at tyrosine 960 inhibits signal transmission but does not affect its tyrosine kinase activity. Cell. 1988; 54:641-649. [PubMed: 2842060]

Wilden PA, Kahn CR, Siddle K, White MF. Insulin receptor kinase domain autophosphorylation regulates receptor enzymatic function. J Biol Chem. 1992; 267:16660-16668. [PubMed: 1322912]

Wolstenholme AJ, Fairweather I, Prichard R, von Samson-Himmelstjerna G, Sangster NC. Drug resistance in veterinary helminths. Trends Parasitol. 2004; 20:469-476. [PubMed: 15363440]

Yamamoto T, Davis CG, Brown MS, Schneider WJ, Casey ML, Goldstein JL, Russell DW. The human LDL receptor: a cysteine-rich protein with multiple Alu sequences in its mRNA. Cell. 1984; 39:27-38. [PubMed: 6091915]

Yen K, Narasimhan SD, Tissenbaum HA. DAF-16/Forkhead box O transcription factor: many paths to a single Fork(head) in the road. Antioxid Redox Signal. 2011; 14:623-634. [PubMed: 20673162] 


\begin{tabular}{|c|c|c|c|}
\hline $\mathrm{pL}-\mathrm{CG} 2-$ & $\mathrm{Ce}$-daf-2 promoter & $g f p$ & unc-54 3'UTR \\
\hline pL-HG2- & $H c-d a f-2$ promoter & $g f p$ & unc-54 3'UTR \\
\hline \multirow[b]{2}{*}{ pPV238- } & & & \\
\hline & $C e-d a f-2$ promoter & $g f p$ & unc-54 3' UTR \\
\hline \multirow{3}{*}{$\mathrm{pL}-\mathrm{CD} 2-$} & & & \\
\hline & Ce-daf-2 promoter & $C e-d a f-2$ & unc-54 3'UTR \\
\hline & & & \\
\hline pL-HD2- & Ce-daf-2 promoter & $H c-d a f-2$ & unc-54 3'UTR \\
\hline
\end{tabular}

Fig. 1.

Cloning strategy for reporter and rescuing constructs. The constructs containing the Caenorhabditis elegans Ce-daf-2 promoter (pL-CG2) and the Haemonchus contortus Hcdaf-2 promoter (pL-HG2) were made based on pPD95.75 by overlap extension PCR.

Rescuing constructs containing coding sequences of Ce-daf-2 (pL-CD2) and Hc-daf-2 (pLHD2) were made by removing the $g f p$ coding sequence from pPV238 (Massey et al., 2013) and linking the appropriate cDNA. A, B and P represent the restriction sites for AgeI, BstZ17I and PstI, respectively. UTR, untranslated region. 


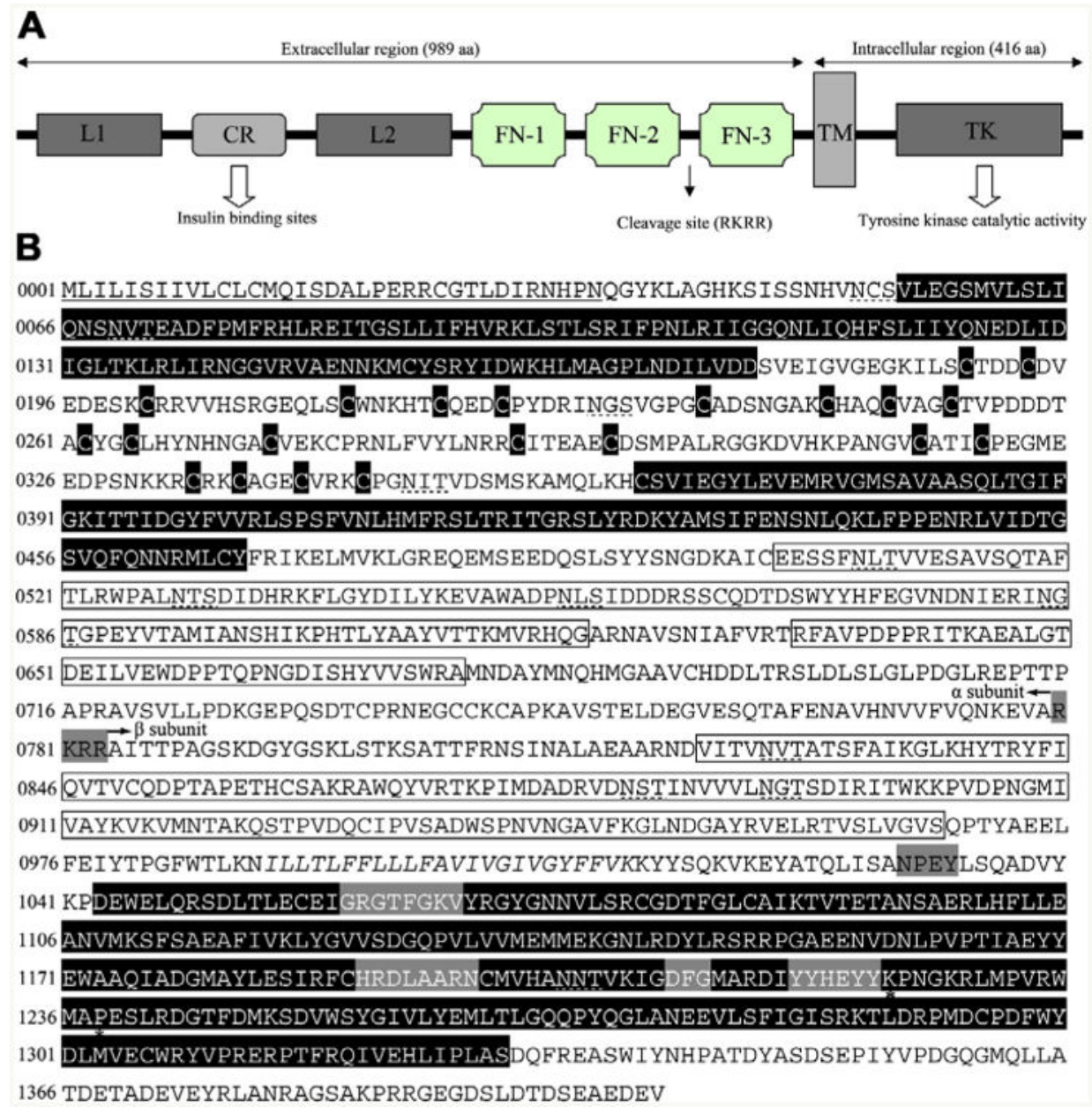

Fig. 2.

Insulin-like receptor of Haemonchus contortus consisting of representative structural domains. (A) Domain structure of the insulin-like receptor of Haemonchus contortus. Analysis of the amino acid sequence for the insulin-like receptor predicted all of the characteristic domains of insulin-like receptors from other taxa, including ligand binding loop 1 (L1) and loop 2 (L2); the cysteine-rich region (CR); three fibronectin type domains (FN-1, FN-2 and FN-3); the transmembrane domain (TM); and a tyrosine kinase domain (TK) (Konrad et al., 2003). (B) Protein sequence and structural features of the insulin-like receptor of $H$. contortus ( $H c$-DAF-2). The putative receptor $\mathrm{L}$ domains, cysteine residues of the CR domain and a TK domain are black boxes with white lettering, the FN domains are boxed. The TM region is italicised and conserved domains (GXGXXG, HRDLAARN, DFG and YXXXYY) (White et al., 1988) are boxed by a grey background. Further indicated are the potential proteolytic cleavage site RKRR (grey box) which divided the Hc-DAF-2 into a subunit and $\beta$ subunit as well as the juxtamembrane NPxY and the $\mathrm{Mg}^{2+}$ binding domain. Two residues (K1224 and P1238) are marked by asterisks, which are highly conserved in the activation loop and might be involved in interaction with downstream signalling proteins (Hubbard, 1997; Massey et al., 2013). The signal peptide is underlined and the putative Nlinked glycosylation sites (NxT/S) are marked with dashed lines. 


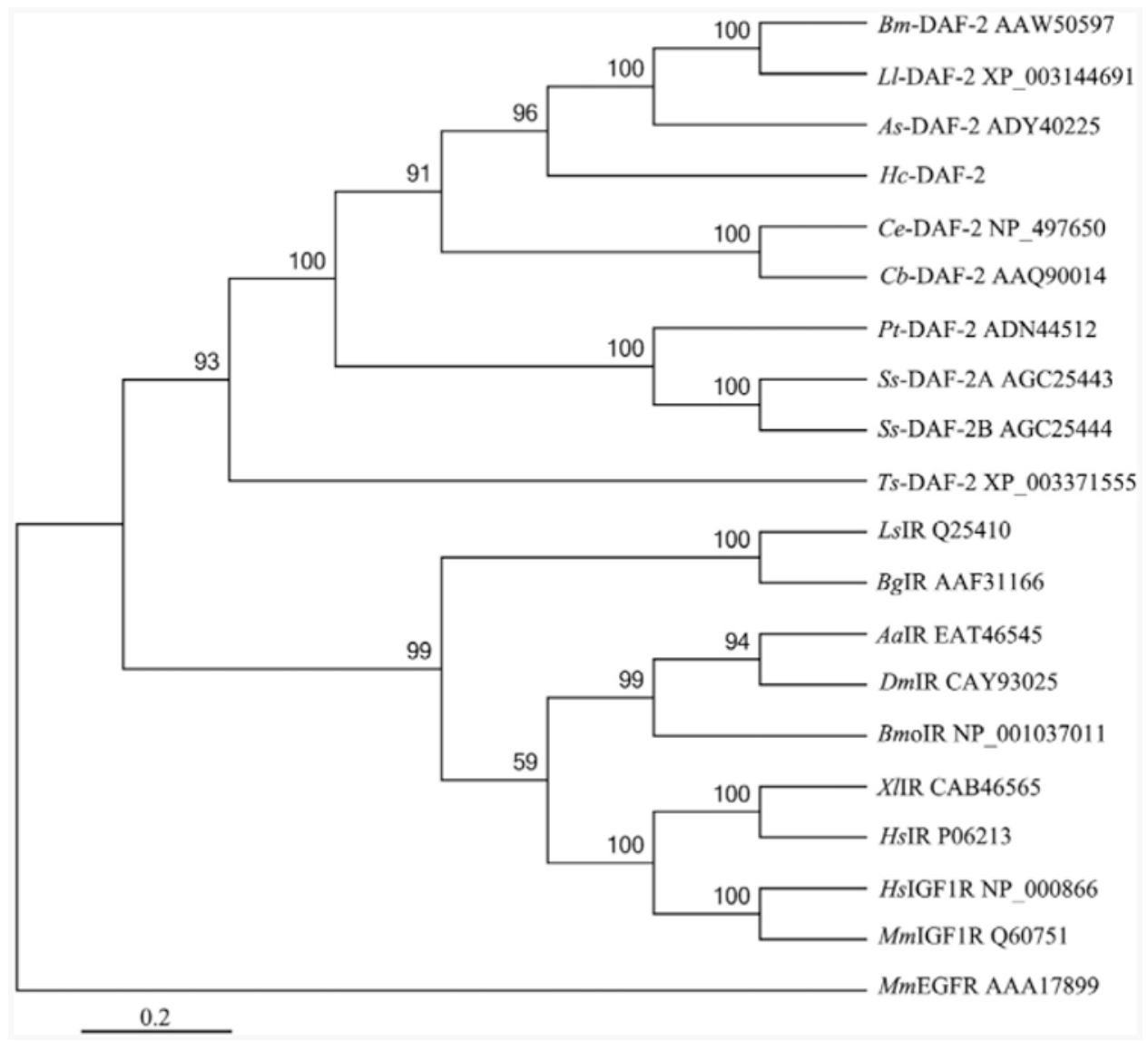

Fig. 3.

A rooted neighbour joining tree showing the relationships of Haemonchus contortus insulinlike receptor $\mathrm{Hc}$-DAF-2 to the insulin-like receptors of nine nematodes and nine nonnematodes. The tree was calculated using the Jones-Taylor-Thornton model in the MEGA program version 5.0. Bootstrap values above or below the branches (1000 iterations) are shown for robust clades (>50\%). These 18 species include nine nematodes (Brugia malayi, Bm-DAF-2; Loa loa, Ll-DAF-2; Ascaris suum, As-DAF-2; Caenorhabditis elegans, CeDAF-2; Caenorhabditis briggsae, Cb-DAF-2; Parastrongyloides trichosuri, Pt-DAF-2; Strongyloides stercoralis, Ss-DAF-2A and Ss-DAF-2B; Trichinella spiralis, Ts-DAF-2), Molluscs (Lymnaea stagnalis, LsIR; Biomphalaria glabrata, BgIR), Insects (Aedes aegypti, AaIR; Drosophila melanogaster, DmIR; Bombyx mori, BmoIR), Vertebrates (Xenopus laevis, XlIR; Homo sapiens, HsIR; Homo sapiens, HsIGF1R; Mus musculus, MmIGF1R). Their corresponding accession numbers are listed on the right of each species. Mus musculus EGFR (MmEGFR) was used as the outgroup. 


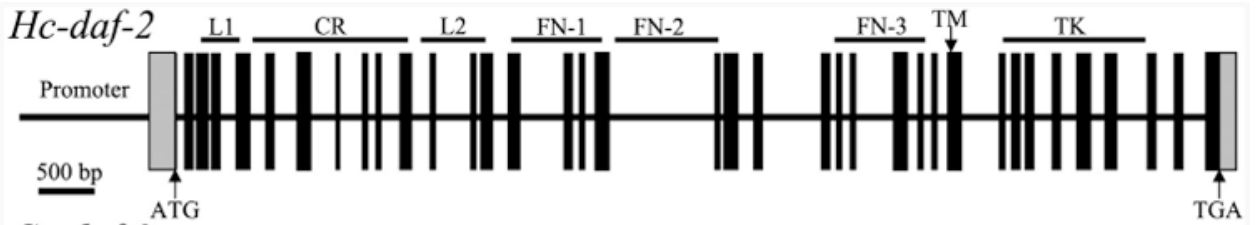

\section{Ce-daf-2}

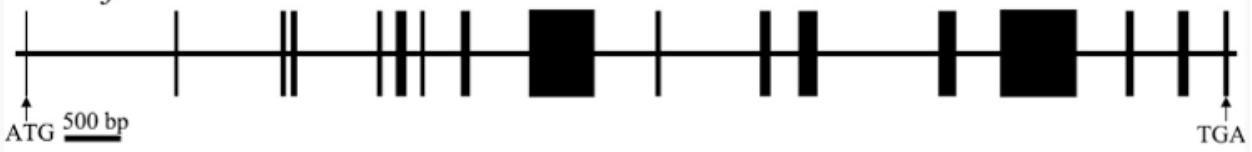

Ss-daf-2a

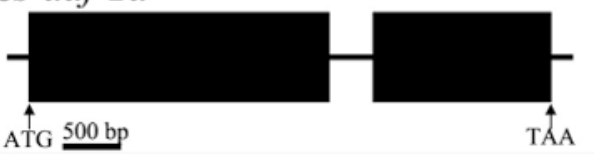

Ss-daf-2b

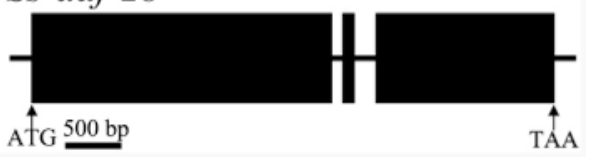

Fig. 4.

Schematic diagram showing the genomic organization of daf-2 from Haemonchus contortus (Hc-daf-2), Caenorhabditis elegans (Ce-daf-2) (Kimura et al., 1997) and Strongyloides stercoralis (Ss-daf-2a and Ss-daf-2b) (Massey et al., 2013). Black boxes represent exons. The lines between the exons represent introns. The structural domains encoded by $\mathrm{Hc}$-daf-2 are marked on the top of diagram of $H c-d a f-2$ gene, located to the corresponding positions. Arrows indicate the start (ATG) or stop codon (TGA). L, ligand binding loop; CR, cysteinerich region; FN, fibronectin type domains; TM, transmembrane domain; TK, tyrosine kinase domain. 


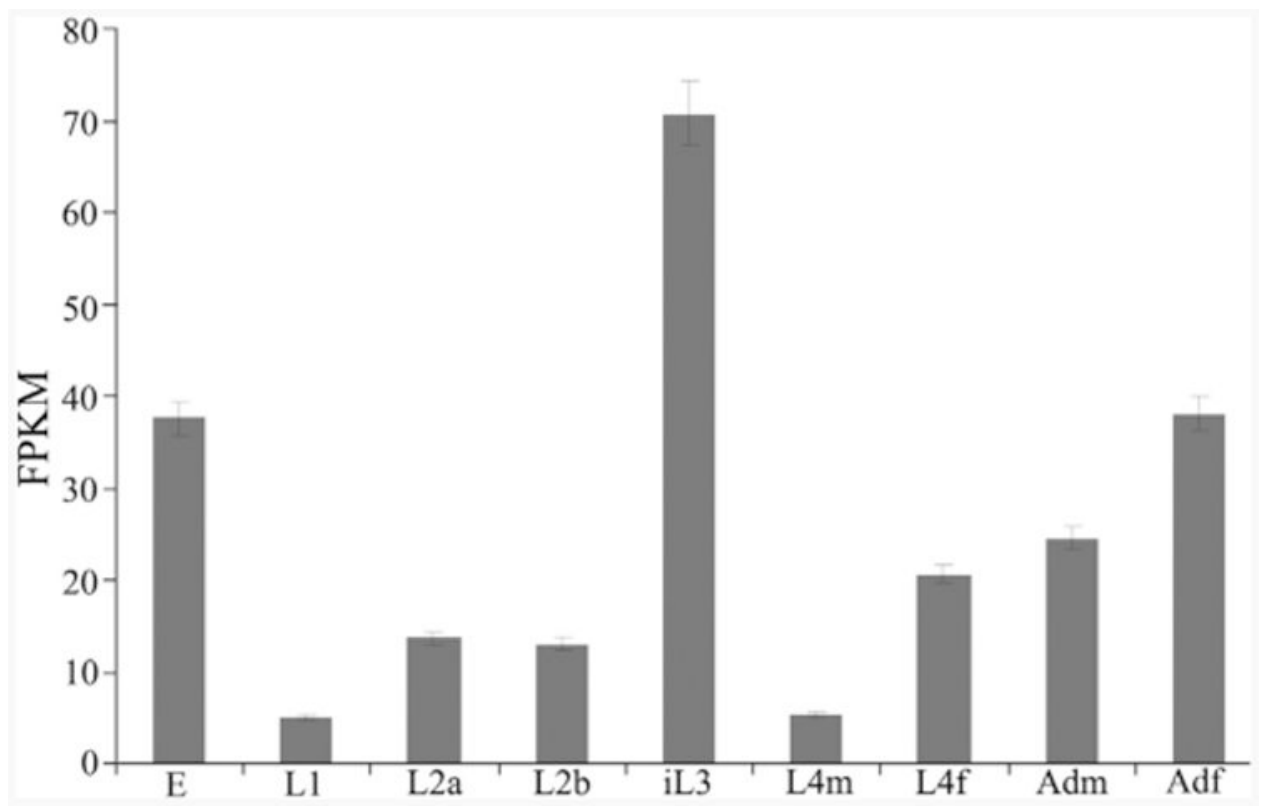

Fig. 5.

Transcriptional profile of Hc-daf-2 in different developmental stages of Haemonchus contortus. Transcript abundances were compared in eight developmental stages, each in biological triplicate $(n=3)$. Eight developmental stages as follows: eggs $(\mathrm{E}), \mathrm{L} 1, \mathrm{~L} 2$, infective L3 (iL3), the L4 males (L4m), the L4 females (L4f); adult males (Adm), adult females (Adf). Transcript abundances were counted as fragments per kilobase of coding exon per million mapped reads (FPKM). Error bars represent $95 \%$ confidence intervals. 

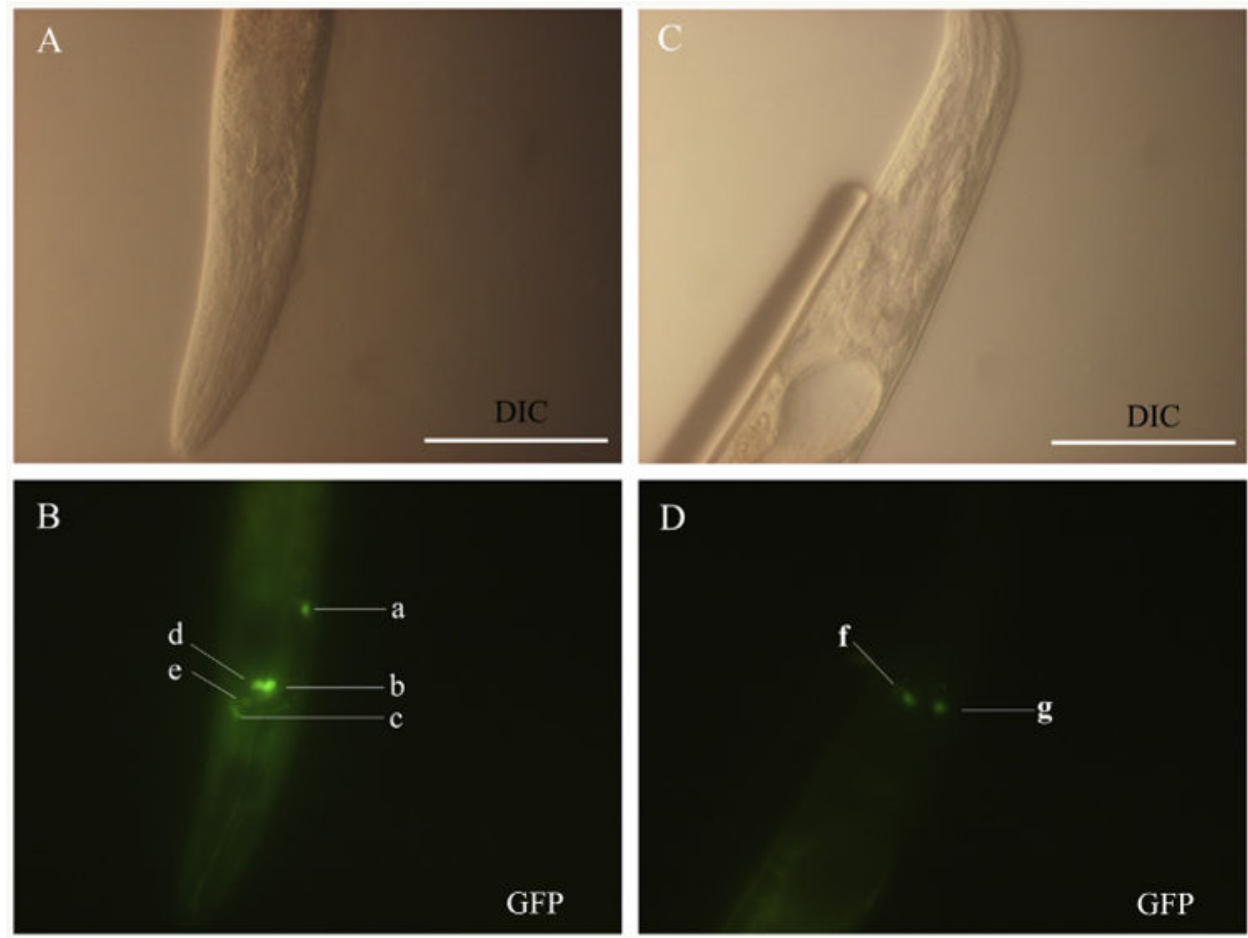

Fig. 6.

Representative expression profiles displayed in Caenorhabditis elegans using two GFP constructs, pL-CG2 and pL-HG2 (cf. Fig. 1). (A and B) Differential interference contrast (DIC) and fluorescence images of a N2 (wild type) L3 using the construct Ce-daf-2 p: :gfp (pL-CG2), respectively. GFP reporter expression was present in the head neuron (a), amphidial neurons including ASH (b), ADF (d) and AWA (e), and nerve ring (c). (C and D) DIC and fluorescence images showing the expression of construct Haemonchus contortus Hc-daf-2 p: :gfp (pL-HG2) in L3 stage of a N2 C. elegans. GFP reporter expression was present in amphidial neuron AWA (f and g). Scale bars $=50 \mu \mathrm{m}$. 


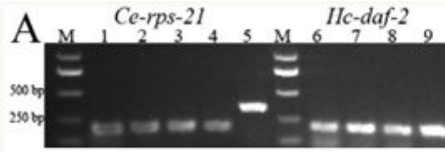

B
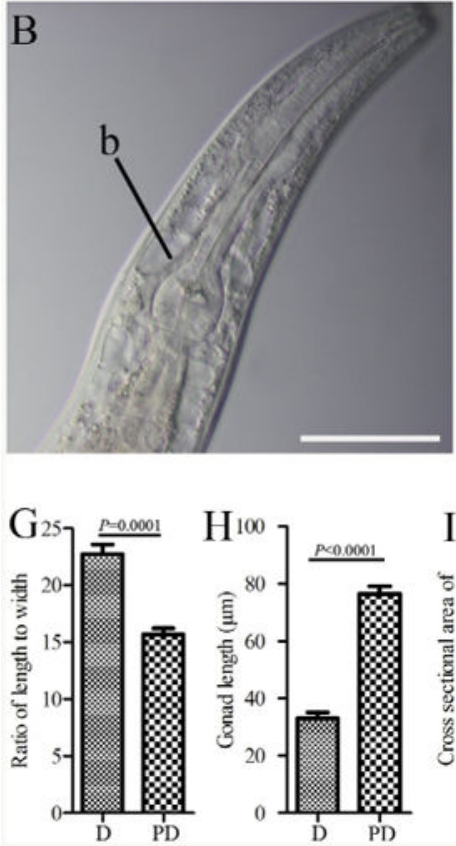
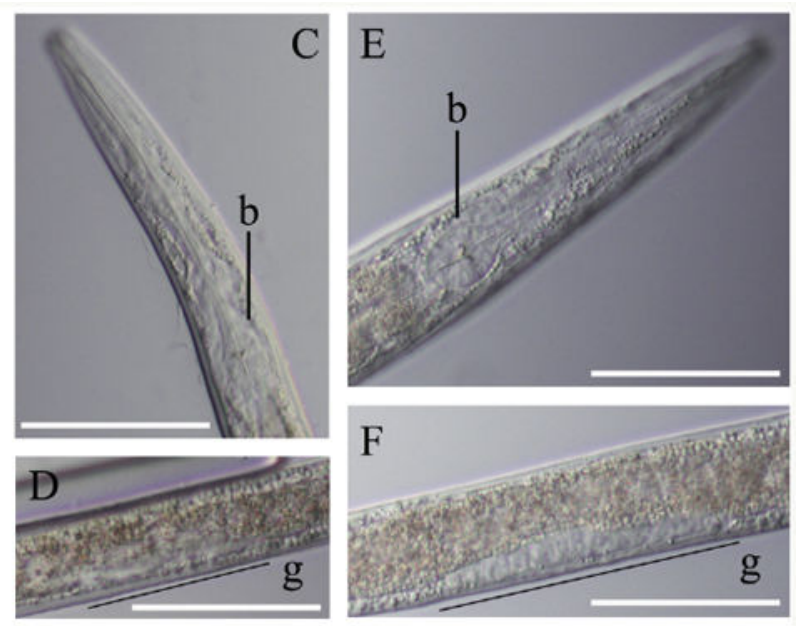

- N-D $\square \mathrm{D} \square \mathrm{PD}$
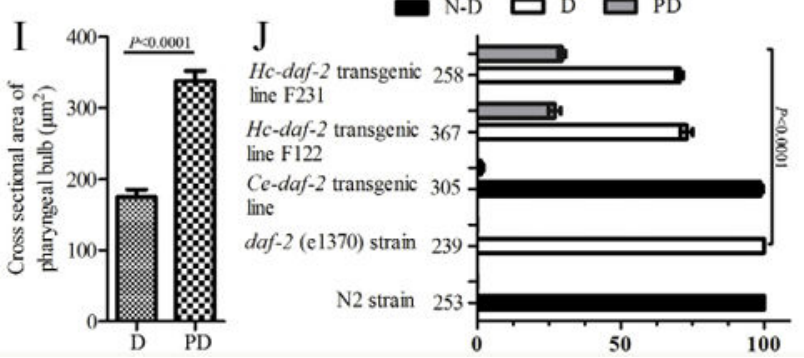

Fig. 7.

Results of dauer developmental assays on mutant and transgenic Caenorhaboditis elegans (Ce) strains. (A) Reverse transcriptase (RT)-PCR to detect the transcription of Haemonchus contortus Hc-daf-2-specific mRNA in daf-2 (e1370) transgenic lines. The constitutively expressed mRNA encoding the ribosomal protein small subunit RPS-21 (Ce-rps-21) was used as a loading control. The Ce-daf-2 transgenic lines were transformed with pL-CD2, and the $H c$-daf-2 transgenic lines were transformed with pL-HD2. RNA was extracted from the transgenic worms exhibiting the roller phenotype. Templates are as follows: lanes 1-4 or 69 represent $H c$-daf-2 transformed lines F121, F122, F231, F232, respectively; lane 5 is $C$. elegans genomic DNA; M, bp size marker. (B - J) Results of dauer-switching assays on well-fed worms from genetic line N2 and daf-2 (e1370) mutants transformed with the indicated transgenes as differential interference contrast (DIC) images. b, bulb; g, gonad. Scale bars $(\mathrm{B}-\mathrm{F})=50 \mathrm{~lm}$. (B) Caenorhaboditis elegans transgenic line expressing Ce-daf-2 mRNA in a daf-2 (e1370) mutant strain; (C and D) C. elegans dauer from a daf-2 (e1370) strain; (E and F) C. elegans transgenic line expressing Hc-daf-2 mRNA in a daf-2 (e1370) mutant strain; $(\mathrm{G})$ ratio of body length to body width between dauer (D) and partial dauer (PD) larvae; (H) comarpison of gonad length between dauer and partial dauer larvae; (I) cross-sectional area of the pharyngeal bulb between dauer and partial dauer larvae; (J) percentage of total population in transgenic lines and controls. Numbers on the left of the Xaxis represent the total number of worms counted for each line. $P \leq 0.0001$ denotes a statistically significant difference between dauer, partial dauer and non-dauer (N-D) larval development in the parental daf-2 (e1370) strain. 